\title{
Empirical Aesthetics: An overview
}

\author{
Marcos Nadal ${ }^{1}$ and Oshin Vartanian ${ }^{2}$
}

${ }^{1}$ Human Evolution and Cognition Group, Department of Psychology, University of the Balearic Islands, Palma, Spain.

${ }^{2}$ Department of Psychology, University of Toronto, Toronto, ON, Canada.

\begin{abstract}
This chapter offers a general overview of Empirical Aesthetics. It begins with a definition of the field's main goals, a summary of its history from its modern foundations to the 1990 s, and an introduction to contemporary accounts of aesthetic appreciation. We then highlight the key components of Empirical Aesthetics (object, person, and context), which provide the basic organization for the book, and summarize the field's basic methods. We end by presenting the subdomains of Empirical Aesthetics, and the neighboring fields it interacts with.
\end{abstract}

Keywords: Empirical Aesthetics, scientific field, history, methods, trends, challenges.

To appear as: Nadal, M. \& Vartanian, O. (2021). Empirical Aesthetics: An overview. In M. Nadal \& O. Vartanian (Eds.), The Oxford Handbook of Empirical Aesthetics. New York: Oxford University Press. 


\section{Empirical Aesthetics: An overview}

\section{What is Empirical Aesthetics?}

Gustav T. Fechner $(1871,1876)$ had high hopes for Empirical Aesthetics. He expected it to evolve into a unified system of general principles of beauty and art. Fechner's Empirical Aesthetics, thus, had the same goals as philosophy, but it progressed in the opposite direction. Whereas philosophical aesthetics began "from above", with general principles that could then be applied to specific cases, Empirical Aesthetics began "from below." Aesthetics from below meant dealing first with the most basic elements and facts of aesthetics. It meant, specifically, explaining the reasons for liking and disliking particular cases, and why objects give pleasure or displeasure. From these explanations, a series of principles could then be deduced, which would eventually coalesce into a comprehensive system of beauty and the arts. Fechner, thus, conceived Empirical Aesthetics as the scientific investigation of beauty and art that begins by collecting specific facts that can later be used to build up general principles and, eventually, a general system of aesthetics.

A century later, this general system of aesthetics was still not in sight. Empirical Aesthetics had not even made much progress moving from the particular cases to the general principles (see section 2, and Chapter 2). Daniel E. Berlyne summarized the achievements of a century-worth of research in Empirical Aesthetics as "relatively sparse and, on the whole, not profoundly enlightening” (Berlyne, 1974, p. 5). Berlyne (1971, 1974) attributed the lack of meaningful progress to unfounded assumptions, outdated theories, and obsolete methods. So, he set out to place Empirical Aesthetics within a general information-theory and motivational framework and to develop a new suite of methods. Berlyne's (1974) "new experimental aesthetics" differed from Fechner's "old experimental aesthetics" in that it focused on properties that modified arousal levels, its explanations were grounded in 
motivational mechanisms, it studied nonverbal behavior as well as verbal judgments, and it did not aspire to produce an autonomous aesthetic system, but to show how aesthetic phenomena were the result of common psychological processes. As such, Berlyne (1972) conceived Empirical Aesthetics as the scientific study of the motivational effects of collative properties of stimulus patterns. More specifically, Empirical Aesthetics was the study of how and why structural features make stimuli appear surprising, novel, complex, or ambiguous, how they modulate arousal levels and, consequently, the stimuli's hedonic value, that is to say, their pleasurableness, reward value, and incentive value (Berlyne, 1974).

In the 50 years that have passed since Berlyne (1971) reformulated Empirical Aesthetics via his new experimental aesthetics, the field has grown substantially and has benefited from the addition of many new methods. Berlyne's focus on arousal-related motivational mechanisms turned out to be overly restrictive and simplistic. We now know that liking something, or finding it pleasing, beautiful or attractive, is not merely a matter of responding to its features. We know that liking, pleasingness, beauty, and attractiveness are influenced by momentary personal factors, such as expectations, available information (Chapters 39 and 40), attention and memory (Chapter 33), and by stable personal attributes, such as personality (Chapter 36), age, (Chapter 34), expertise (Chapter 35), aesthetic sensitivity (Chapter 37), and cultural background (Chapter 38), among others. Even the physical context (Chapters 41 and 42) and the social context (Chapter 43) can modulate assessments of liking, pleasingness, beauty, and attractiveness. Indeed, aesthetic appreciation is a good example of the contextual permeability of perception, cognition, and emotion (Bar, 2004; Mesquita, Barrett, \& Smith, 2010). We also know now that aesthetic appreciation cannot be reduced to arousal-boosting or -reducing motivational mechanisms. We know it involves complex interactions between several perceptual, cognitive, and affective processes - realized in the form of top-down and bottom-up processes (Chatterjee \& 
Vartanian, 2014; Leder, Belke, Oeberst, \& Augustin, 2004; Skov, 2019). Berlyne was right when he argued that the phenomena we consider aesthetic rely on general neural and psychological mechanisms, although the data and methods available to him could not reveal the diversity and complexity of those mechanisms.

Clearly, the knowledge we have gained and the methods we have added since Berlyne (1971, 1974) refashioned Empirical Aesthetics, and certainly since Fechner $(1871,1876)$ created the domain, require broadening the definition of Empirical Aesthetics. The most inclusive definition would conceive Empirical Aesthetics as the scientific field that uses empirical methods to study aesthetics. Although tautological, this definition specifies the features of the knowledge Empirical Aesthetics seeks and generates (scientific knowledge), the kind of methods it uses (empirical methods), and what the knowledge it seeks and generates is about (aesthetics). It avoids Fechner's promise of a general system of art and aesthetics, and Berlyne's reduction of all explanation to a single major mechanism. The scientific and empirical aspects of this definition are probably quite uncontroversial, but there will surely be disagreement among empirical aestheticians today about what aesthetics is. So, let us first see what it means that Empirical Aesthetics is a scientific field, and why it is that it uses empirical methods. We can then turn to the contentious issue of what aesthetics is or is not about.

\subsection{Empirical Aesthetics is a scientific field}

Science relies on a system of procedures that generate a particular kind of knowledge about some natural (as opposed to supernatural) phenomenon. The kind of knowledge science produces is descriptive and explanatory, testable, replicable, revisable, incremental and collective. Thus, Empirical Aesthetics seeks and produces a different kind of knowledge than 
the one Philosophical Aesthetics has done (Chapter 4). What, specifically, does it entail that Empirical Aesthetics is a scientific domain?

- First, that, as with research in biology, medicine, and other scientific disciplines, research in Empirical Aesthetics occurs with the understanding that its focus of study is coextensive with the natural world. As such, research findings and inferences emerging in Empirical Aesthetics must be informed by and can potentially contribute to knowledge in other domains of natural science.

- Second, that Empirical Aesthetics generates descriptive knowledge by recording data as they are observed, as with surveys and questionnaires, natural observation, and central tendency and dispersion summary statistics. It also generates explanatory knowledge when it uses experimental methods. Experiments involve the manipulation of one or several factors and the observation of the effects on one or several outcomes under controlled conditions. Experimental control is indispensable for explanations in terms of causes and effects, and the associated ability to draw causal inferences.

- Third, it means that knowledge in Empirical Aesthetics is not disjointed, but assembled into scientific theories. Empirical Aesthetics formulates scientific theories based on the descriptive and explanatory knowledge it generates. It uses those theories to make predictions about future results, in the form of hypotheses, and to interpret those results. Thus, the theories of Empirical Aesthetics should make clear and falsifiable predictions, be consistent with existing results, and make accurate predictions of new results. A good scientific theory is able to accurately describe (what), identify the underlying mechanisms (how), and interpret (why) observations in its domain (Dayan \& Abbott, 2001, p. xiii). 
- Fourth, it means that these descriptive and explanatory results can be-and should be-tested again in replication studies. Many tenets in in Empirical Aesthetics, and psychology and neuroscience in general, rest only on single experiments, even though some are taught and presented in handbooks as established facts. The knowledge generated by Empirical Aesthetics should be reliable, but reliability is difficult to measure unless experiments are repeated and replicated. Some of these replications might confirm previous results, and support their conclusions, while others might not. Reiterated failures to replicate should lead to the rejection of those tenets, and to new alternative explanations. In this sense, attempts at falsification must be central to the practice of the science.

- Fifth, it means that the findings in Empirical Aesthetics are revisable. It is not a weakness of scientific knowledge that it is revisable and provisional; it is one of its fundamental strengths. With revision comes progress, so the more a scientific field revises it knowledge, the faster it progresses. A scientific domain is alive when there is room for major improvements to current knowledge, but lifeless when there is little room for improvement, if that is possible at all. The revisability of scientific knowledge is what distinguishes it from dogma. Scientific dogmatism—resistance to revise ideas held on to as truths despite challenging results - has more in common with faith than with science.

- Sixth, it means that Empirical Aesthetics commonly progresses through the piecemeal accretion of results produced by different teams of researchers. New findings, or a reinterpretation of old ones, might occasionally make a field leap forward, and some individuals have a pivotal impact on progress, as Fechner and Berlyne undoubtedly had on Empirical Aesthetics. But these are the exceptions. As a rule, science is an incremental and collective endeavor. 


\subsection{Empirical Aesthetics uses empirical methods}

Empirical methods are those that produce data through observation and measurement. Empirical data are fundamental to the testability, replicability, and revisability of scientific knowledge. Some of the early methods of Empirical Aesthetics were derived from Psychophysics, and they continue to be prominent today. They involve the measurement of people's responses to controlled variations in stimulus features, such as proportion, symmetry, complexity, or predictability. As neighboring fields advanced, Empirical Aesthetics also borrowed methods from Behavioral Psychology, Cognitive Psychology and, more recently, Cognitive Neuroscience. The methods now available to Empirical Aesthetics allow recording verbal judgments, choices and preferences, exploratory time and movements, implicit measures, eye movements, psychophysiological measures, temporal and spatial patterns of brain activity, and the effects of brain stimulation, among others. In addition, technological innovations have made it possible to use several of these methods simultaneously, enhancing greatly our knowledge of various phenomena across multiple levels of measurement (see chapters in section 2).

Collecting, analyzing, and systematically organizing observations is essential to the goals of Empirical Aesthetics. However, this does not mean that there is no theorizing or conceptual work to be done by researchers. Observations are valuable and meaningful to the extent that they have implications for theory. In science, a theory is a formal explanation of a substantial set of observations. The goal of scientific theories is usually to reveal the mechanisms whereby a set of observed or hypothetical causes lead to a set of observed or hypothetical consequences. For instance, Berlyne's (1971) theory mentioned above was intended to explain how certain stimulus properties (i.e., observed causes) induced certain arousal dynamics (i.e., hypothesized consequences) that, in turn, lead to (i.e., hypothesized 
causes) pleasure or displeasure (i.e., observed consequences). Theories are the source of the interpretation of patterns of collected observations, and the source of predictions about future observations. Indeed, it is debatable whether atheoretical observation is even possible, given that our decisions regarding what to observe are influenced heavily by expectations. Thus, Empirical Aesthetics does not collect observations for the sake of it, but rather to improve its explanations and predictions.

\subsection{Empirical Aesthetics studies aesthetics}

Aesthetics is a concept that means different things to different people (Anglada-Tort \& Skov, 2020). In the Western tradition of thinking, aesthetics has had two main foci: making and appreciating art, and the appreciation of the value of certain perceptual features (Levinson, 2003; Sparshott, 1963). This dual focus made sense to, and was adopted by, Fechner and others when they applied empirical methods to aesthetics in the late $19^{\text {th }}$ century. Külpe (1897), for instance, wrote that "The objects investigated by the science are on the one hand judgments of aesthetic pleasure and displeasure, and on the other works of art. The separation of the two groups shows that there was truth in the old distinction between a philosophy of beauty and a philosophy of art. The aesthetic judgment extends beyond works of art, since there is a beauty of nature as well as of art; and works of art give us more than the aesthetic judgment, since when we have decided as to the pleasingness or displeasingness of their impression we can go on to discuss the conditions of their origination, the relation between portrayal and portrayed, between the form and contents, copy and model, etc. etc." (Külpe, 1897, p. 88).

Berlyne (1972) agreed that Empirical Aesthetics should study art and aesthetic appreciation, but he was wary of grounding the definition of the field on either aspect. Such a definition, he believed, would misleadingly suggest that aesthetics was a separate domain of 
human life, and would cut Empirical Aesthetics off from the rest of the behavioral and brain sciences: "The essentially superstitious view that the aesthetic realm is sharply distinct from the rest of life and governed by principles peculiar to itself has long been a bugbear." (Berlyne, 1972, p. 304).

Today, Empirical Aesthetics continues to be divided about what makes art and aesthetic experiences unique and different to other kinds of objects and experiences, respectively. The various positions on this topic lie along a continuum. At one pole of the continuum we find researchers who argue that art and aesthetic experience involve unique forms of pleasure or emotion, and that it is therefore important to distinguish aesthetic pleasure, aesthetic emotions or art emotions from non-aesthetic or non-art-based pleasure and emotion (Christensen, 2017; Fingerhut \& Prinz, 2020; Makin, 2017; Menninghaus et al., 2019). At the other pole of the continuum we find researchers who argue that art and aesthetic experience involve the same kind of pleasure and emotions as any other kind of object and experience and that, therefore, the notions of aesthetic pleasure, aesthetic or art emotions are unnecessary and misleading (Berlyne, 1972; Nadal \& Skov, 2018; Skov \& Nadal, 2019, 2020). Somewhere between both of these poles we find the views of researchers who have argued that aesthetic experiences arise from a unique combination of general cognitive and affective processes (Leder et al., 2004; Pelowski, Markey, Forster, Gerger, \& Leder, 2017), and those that have argued that aesthetic emotion is ordinary emotion lacking its motivational component (Chatterjee, 2014; Chatterjee \& Vartanian, 2014).

\section{A brief history of Empirical Aesthetics}

\subsection{Founding Empirical Aesthetics}

If Psychophysics is considered as the oldest domain of experimental psychology, then Empirical Aesthetics is rightly considered as the second oldest (Berlyne, 1972; Seeley, 
2014a). Both were founded by Gustav Theodor Fechner: in 1860 he published his Elements of Psychophysics (Fechner, 1860), and in 1876, Preschool of Aesthetics (Fechner, 1876). His approach to aesthetics was shaped by the priority he gave to empirical knowledge, and his view that striving for pleasure was a major force driving human behavior. As we saw in the previous section, Fechner advocated an aesthetics from below, that is to say, starting with individuals' likes and dislikes, choices and preferences. Pooling together and averaging the results from many people would level out individual peculiarities and reveal the laws that explain how certain sensory features, and their combinations, give rise to pleasure or displeasure and, therefore liking or disliking. To achieve this goal, he developed three methods (Chapter 3): The method of choice, which requires participants to select among several alternatives the one they find most pleasing; the method of production, which requires them to produce pleasing examples of simple shapes or figures; and the method of use, which measures (non-purposeful) features in objects that are manufactured, bought and used, under the assumption that the most common ones are the most pleasing ones. He also deduced a number of principles that underlie aesthetic pleasure: that sensory impressions must occur above a certain threshold of pleasure, that objects that give rise to aesthetic pleasure are often composite and manifold, that the features should be aligned toward the same end and be harmonious, and so on.

Fechner had a monumental impact on psychology, but he had no school or students to follow his program. It came to Wundt's students to set Empirical Aesthetics into motion (see Chapter 2). Among their most influential works were Witmer's (1894) study of the effects of the proportion of linear figures on pleasingness judgments, Martin's (1906) systematic examination of Fechner's principles of aesthetics using the methods of psychophysics and simple figures consisting of lines that differed in orientation, length, curvature and thickness, 
and Külpe's $(1907,1921)$ refinement, systematization, and extension of Fechner's methods and principles.

\subsection{Empirical Aesthetics during the decades of behaviorism}

Whereas German psychology in the late $19^{\text {th }}$ and early $20^{\text {th }}$ centuries focused on the what and how of consciousness, that is to say, on what takes place in conscious sensation, feeling and thinking, and how it takes place, American psychology focused on the why. Its goal was to understand how the mind enabled humans to adapt to their environment.

Adaptation implies the competition among individuals with different traits or capacities that confer them greater or lesser advantages in a given context. So, when the American psychologists turned their attention to Empirical Aesthetics, in the early decades of the $20^{\text {th }}$ century, it was with a focus on individual differences (H. Clark, Quackenbush, \& Washburn, 1913; Thorndike, 1917).

During the behaviorist decades it became paramount to understand why some stimuli are more rewarding. Many studies were conducted in the musical domain on the affective value of single tones, simultaneous pairs of tones, simple tone sequences, different cadences, major and minor modes, consonance and dissonance, variations in rhythm, and repeated exposure (Edmonds \& Smith, 1923; Farnsworth, 1925, 1926a-b, Guernsey, 1928; Heinlein, 1925, 1928; Hevner, 1935b, 1936; Ortmann, 1928, 1926). In the visual domain, researchers studied people's affective responses and associations elicited by simple lines and forms, the consistency and variability in people's responses to paintings, the effects of different kinds of information on the appreciation of paintings, and the effect of age and development on aesthetic preference, among other topics (Barnhart, 1940; Brighouse, 1939b, 1939a; Cahalan, 1939; Clair, 1939; Davis, 1933; Farnsworth, 1932; Hevner, 1935a; Hevner \& Mueller, 1939; Israeli, 1928; Lundholm, 1921; Poffenberger \& Barrows, 1924; Voss, 1939; Weber, 1931; 
Yokoyama, 1921). But there was no matching the torrent of studies on preferences for colors and color combinations, on the expressiveness of colors, and on the influence of personality, age, and culture on those phenomena (e.g., Allesch, 1925; Garth, 1924; Garth \& Collado, 1929; Geissler, 1917; Katz \& Breed, 1922; Michaels, 1924; Staples, 1931; Stratton, 1923; Washburn, Haight, \& Regensburg, 1921).

\subsection{Psychometric Empirical Aesthetics}

The decades of behaviorist hegemony were also the golden age of testing all kinds of psychological processes involved in aesthetics: sensitivity to visual balance and complexity, discrimination and memory for pitch, intensity, consonance, and rhythm, aptitude in design, the appreciation of visual art, literature, and music (Adler, 1929; Barron \& Welsh, 1952; Carroll, 1933; Farnsworth, 1931; Graves, 1948; Guilford \& Guilford, 1931; Heinlein, 1925; Logasa \& Wright, 1930; Madison, 1942; McAdory, 1933; McCarthy, 1930; Meier, 1926, 1942; Meier \& Seashore, 1929; Stanton, 1928; Welsh \& Barron, 1949; Williams, Winter, \& Woods, 1938; Wing, 1941).

Two of the most influential efforts to develop valid and reliable measures of mental abilities for art and aesthetics were those of Seashore and Meier in Iowa, and those of Hans J. Eysenck in London. Carl E. Seashore published the Seashore Measures of Musical Talents, which provided a relatively good index of the receptive side of musical talent. Norman C. Meier and Seashore later applied similar principles to the visual domain, and developed the Meier-Seashore Art Judgment Test (Meier \& Seashore, 1929). A new version followed, the Meier Art Tests: I. Art Judgment (Meier, 1940), and later a new test, the Meier Art Tests: II. Aesthetic Perception (Meier, 1963).

Hans J. Eysenck identified a general objective factor of aesthetic appreciation that distinguished people who were better at identifying beauty in objects and designs from those 
who were worse at doing so. A second bipolar factor distinguished participants according to the style of art they preferred (Eysenck, 1941c). Eysenck believed that this factor was universal and innate (Eysenck, 1941a, 1941b, 1942, 1981). Later in his life, he developed the Visual Aesthetic Sensitivity Test (VAST) in collaboration with the German artist and designer Karl Otto Götz to measure individual differences in good taste (Chan, Eysenck, \& Götz, 1980; Götz, Borisy, Lynn, \& Eysenck, 1979; Iwawaki, Eysenck, \& Götz, 1979).

\subsection{The Gestalt school of psychology}

Gestalt's most significant contribution to psychology was the school's conception of perception and understanding as emergent processes that go beyond the mere recording of the elements in the stimulus. They suggested a number of grouping principles, such as proximity, continuation, similarity or closure, which organized parts of the visual scene into wholes, such as objects, clusters, and overall scenes. These and other Gestalt principles were applied to art and aesthetics by Rudolf Arnheim $(1964,1966,1969)$. He explained many traditional aspects of training in "Beaux Arts" schools in terms of Gestalt's principles of organization: balance, symmetry, composition, and dynamical complexity, by which he meant an optimal trade-off between order and complexity. Even more importantly, Arnheim argued that aesthetic experiences arise not from the mere automatic and passive recording of aspects of the visual field, but from the awareness of dynamic forces inherent to the stimuli. This awareness is attained by the integration of two sources of information: the structured configurations received from the image and the patterns towards which the individual is oriented by virtue of his experience and disposition. The overall configuration of these dynamical visual forces constitutes what Arnheim (1974) referred to as the structural skeleton of the design. To Arnheim, the essence of an artwork is to create a dynamic whole by integrating this structural skeleton with the depicted subject matter. 


\subsection{Berlyne's new Experimental Aesthetics}

Daniel Berlyne is responsible for revitalizing the scientific study of art and aesthetics during the 1960s and 1970s. His research program, known as Psychobiological Aesthetics, became the starting point for contemporary Empirical Aesthetics. Its main objective was to detail a set of motivational laws that could explain people's preference for certain kinds of stimuli. From this point of view, the hedonic tone induced by a stimulus - the power to reward an operant response and to generate preference or pleasure expressed through verbal assessments (Berlyne, 1971) — depended on the level of arousal that it was capable of eliciting in relation to the organism's current arousal level. Given that organisms tend to search for the optimal hedonic value, they would tend to expose themselves to different stimuli as a function of their arousal potential.

Berlyne (1971) noted three classes of variables that determine a given stimulus' arousal potential, mainly through the amount of information transmitted to the organism. These were: (i) psychophysical variables, such as brightness, saturation, predominant wavelength, and so on; (ii) ecological variables, including those elements that might have acquired associations with biologically relevant events or activities; (iii) collative properties, such as novelty, surprise, complexity, ambiguity, or asymmetry. Collative properties refer to aspects of the object that have the potential to increase or reduce arousal because of the way and extent to which they compare with previously experienced objects. In relation to aesthetics and art, Berlyne suggested that interest and preference for an image depend primarily on how complex such a stimulus appears to the viewer (Berlyne, 1963; Berlyne, Ogilvie, \& Parham, 1968). Perceived complexity, in turn, is related to such factors as the regularity of the pattern, the number of elements that form the scene, their heterogeneity, or the irregularity of the forms (Berlyne, 1970). Thus, under normal conditions, that is to say, 
with an intermediate level of arousal, people were expected to prefer intermediately complex artworks over highly complex or very simple ones, regardless of modality and medium. Depending on the current arousal level, such preferences could shift toward more complex or simpler objects.

\subsection{Martindale's connectionist prototype model}

If Berlyne's work is the first step toward a cognitive approach to Empirical Aesthetics, Colin Martindale's is its consolidation. Martindale developed a connectionist model that explained the effects of prototypicality on aesthetic preference as a result of basic cognitive functioning (Martindale, 1984, 1988). He modelled cognition as a large network of interconnected cognitive units (i.e., nodes), segregated into a number of analyzers. The output of these sensory analyzers constitutes the input for a number of perceptual or gnostic analyzers. These perceptual analyzers include a series of cognitive units at the lower levels which code the distinctive features. Specific excitement patterns of feature units define units in the next level, and so on up the hierarchy in the perceptual analyzers. Hence, a reduced number of feature units are able to define a vast number of unitary percepts. The output from perceptual analyzers enters the semantic analyzer, which includes one cognitive unit for each concept a person has. Activity from here is passed on to the episodic analyzer, which contains memories. This analyzer produces outputs which correspond to events coded propositionally.

This architecture could model aesthetic experience: "Apprehension of a work of art of any sort will involve activation of cognitive units in sensory, gnostic, semantic, and episodic analyzers. (...) the pleasure engendered by a work of art will be a positive monotonic function of how activated this entire ensemble of cognitive units is. The more activated the ensemble of units, the more pleasurable an observer will find the stimulus to be". (Martindale, 1988, p. 26). Martindale $(1984,1988)$ hypothesized that prototypical stimuli are 
encoded by stronger cognitive units, and given that aesthetic pleasure is a function of the activation level of cognitive units, prototypical and meaningful stimuli are predicted to be associated with higher levels of aesthetic preference than stimuli which are atypical.

Martindale's experiments confirmed this prediction. They proved that prototypicality accounted for close to 5 times more variance in aesthetic preference than collative variables (Martindale, Moore, \& Borkum, 1990; Martindale, Moore, \& West, 1988). Moreover, Martindale and colleagues (1990) showed that some of the aesthetic effects Berlyne had attributed to complexity actually owed to meaningfulness. Thus, the key determinant of aesthetic appreciation were not collative variables, but prototypicality, which facilitates meaningfulness (Rosch \& Mervis, 1975; Rosch, Mervis, Gray, Johnson, \& Boyes-Braem, 1976).

\section{Contemporary accounts of aesthetic appreciation}

\subsection{Processing fluency}

The world is not an easy place to live in. It is complex and often unpredictable. Our cognitive systems must deal with the barrage of varied kinds of sensations we constantly receive, to create representations of objects and events in the present and to assess their relevance in light of our goals and motivations, to regulate our many homeostatic systems, and to plan for the future based on our past experiences. Not surprisingly, natural selection has endowed cognitive systems with a taste for efficiency and with several means to simplify their tasks. For instance, sorting reality into discrete categories, and abstracting prototypes to represent those categories, saves us much time and effort in navigating the physical and social world. From this point of view, it makes sense, as Martindale (1988) argued, that we should prefer typical exemplars, because they give us more for less: prototypical exemplars convey more information about the category than less prototypical exemplars. There are 
many other examples of cognition's taste for ease and efficiency: we tend to prefer the familiar to the unfamiliar, the clear to the unclear, the symmetrical to the asymmetrical, and so on.

Reber, Schwarz, and Winkielman (2004) noticed that there are many domains in which ease of processing is experienced as pleasant, and several factors that contribute to ease of processing. They suggested that ease of processing might be a general principle of aesthetic appreciation: "The more fluently perceivers can process an object, the more positive their aesthetic response" (Reber et al., 2004, p. 364). This processing fluency model of aesthetic appreciation (see Chapter 19) is based on the premises that some stimuli are easier to process than others, and that ease of processing has hedonic consequences: easy processing is experienced as a pleasant feeling of fluency, whereas difficult processing is experienced as an unpleasant feeling of disfluency. Because we commonly rely on feelings when evaluating objects, we tend to consider objects we subjectively feel as more fluent as also more beautiful, likeable, and attractive (Forster, Leder, \& Ansorge, 2013, 2016). The processing fluency account is appealing because it provides a simple explanation for many scattered findings in empirical aesthetics, and because it is grounded on a general principle of cognition (Jacoby, Kelley, \& Dywan, 1989).

\subsection{The Pleasure-Interest model of aesthetic liking}

We seem to have a mystery on our hands. Berlyne's (1971) arousal account of aesthetic appreciation predicts people will generally prefer objects that are relatively complex, novel, and ambiguous, and there are results that confirm people prefer a moderately arousing challenge (Marin, Lampatz, Wandl, \& H., 2016). In contrast, Reber and colleagues' (2004) fluency account predicts people generally prefer objects that are experienced as easily 
processed, and there are results that confirm this too (Forster et al., 2013). How can we reconcile this discrepancy?

Graf \& Landwehr $(2015 ; 2017)$ developed a dual-processing model, called the Pleasure-Interest model of aesthetic liking, to explain why under some circumstances people prefer a degree of challenge, and why under other circumstances they prefer ease of processing. Their model is based on the distinction between two forms of processing: automatic processing, which is stimulus-driven, and controlled processing, which is perceiver-driven. In some cases, aesthetic judgments are fast and automatic, and will be based primarily on pleasure or displeasure responses to stimuli. In other cases, when the motivation is sufficient, the controlled processing mode becomes engaged, eliciting aesthetic interest. These two processing modes lead to two different forms of liking. Automatic processing leads to pleasure-based liking, which is greatest for easily processed stimuli, and controlled processing leads to interest-based liking due to the reduction in disfluency, which is greatest for challenging stimuli. From this perspective, the arousal and fluency accounts each capture only half of a dual-processing liking system. This model has found support in studies on musical (Omigie et al., 2019) and visual (Miller \& Hübner, 2019; Van Geert \& Wagemans, 2019) preferences.

\subsection{Information processing model of aesthetic appreciation}

Leder and colleagues introduced an information-processing model to account for the interaction of various component processes in the computation of aesthetic experience (Leder et al., 2004). Leder and colleagues' (2004) model is comprised of five information-processing stages that are connected in sequence, as well as through several feedback loops. Information flow is unidirectional in some parts of the model and bidirectional in others, such that certain 
phases involve bottom-up as well as top-down processing. In addition, there is an affective evaluation stream that runs parallel to this sequential stream and receives its output.

The input into the system is an artwork, or an object of aesthetic interest. Then, at each stage, a particular operation is performed on the artwork, therefore extracting various characteristics from it. The first stage involves perceptual analyses. At this stage features such as complexity or symmetry are distilled. For example, there is much research demonstrating that people prefer more to less symmetrical design. According to this model, this information is processed rather early in the stream. This stage is not under the influence of top-down processes, and is stimulus driven. The second stage involves implicit memory integration, where the perceptual information is related to past experience. For example, we know that people prefer colors that are more prototypical. However, we also know that what is deemed prototypical depends in part on personal experience. At this stage people compare what they see to what they know, and this affects their responses to it. This stage is presumed to be under the indirect influence of top-down processes. The third stage involves explicit classification, and this is where expertise comes into play. At this point, the person analyzes content information, and also explicit information about the style of the artwork. There is much evidence demonstrating that expertise affects the way in which artworks are processed, and this is one of the stages where the difference between experts and novices would be apparent.

The penultimate stage is referred to as cognitive mastering, the moment at which interpretation or meaning is imposed on the artwork. Thus, having already distilled its perceptual properties and placed it within self-referential (implicit memory integration) and explicit (explicit classification) contexts, we make sense of what it is that we see. Of course, what one observes is also influenced by expertise in the visual arts, so that different cues become more or less important in giving meaning to the artwork. In the final stage referred to 
as evaluation, we appraise the meaning or interpretation that was placed on the artwork during mastering. This evaluative stage generates two outputs: aesthetic judgment and aesthetic emotion, which are the endpoints of the aesthetic experience. If cognitive mastering is successful and the subject has successfully interpreted the artwork, it will be evaluated as either a good or a poor work of art. Those aesthetic judgments will in turn be accompanied by positive and negative aesthetic emotions, respectively. On the other hand, if cognitive mastering is unsuccessful, then the artwork will likely be evaluated as a poor work of art, and be accompanied by negative aesthetic emotion.

Since its original introduction in 2004, the model has been updated. Leder and Nadal (2014) revised the model to include recent findings on the way emotions (see Chapter 6) and the physical and social context (see Chapters 39-43) shape aesthetic appreciation, and to place the framework into an evolutionary context. Later, Pelowski and colleagues (2017) substantially expanded the scope of the model to account for bottom-up and top-down processes related to the appreciation of art including transformative aesthetic experience, as well as to connect the model's processing stages with activity in brain regions.

\subsection{Neuroaesthetics}

For most of its history, Empirical Aesthetics has relied on the study of patients with brain lesions or neurodegenerative diseases for knowledge about the neural systems underlying aesthetics (Chatterjee, 2004, 2006; Zaidel, 2005). The brain imaging methods developed in the 1990s were added to the methodological stock of Empirical Aesthetics in the 2000s (Nadal, Munar, Capó, Rosselló, \& Cela-Conde, 2008), and have had a transformative effect on the field (Skov, 2019). Researchers can now infer, from observed changes in different indices of neural activity, the brain mechanisms that transform information about the stimulus and other external and internal factors, such as task goals, 
expertise, or verbal primes, into different degrees of liking and disliking. Neuroimaging studies have shown that even the apparently simple judgment of something as likeable involves orchestrating activity in many different networks of brain regions (Skov, 2019).

The results of neurophysiology (Chapter 14), neuroimaging (Chapter 15), and brain stimulation (Chapter 16) studies have shown that aesthetic appreciation involves coordinated activity in three networks of brain regions: prefrontal, parietal, and temporal cortical regions related to evaluative judgment, attentional processing, and memory retrieval; the reward circuit, including cortical and subcortical regions, as well as some of the regulators of this circuit; and a network of low-, mid-, and high-level cortical sensory regions (Nadal, 2013; Nadal \& Pearce, 2011). Meta-analyses confirm that the brain regions most commonly activated in studies of aesthetic appreciation are related to perception and representation of affective value (Brown, Gao, Tisdelle, Eickhoff, \& Liotti, 2011; Chuan-Peng, Huang, Eickhoff, Peng, \& Sui, 2020; Vartanian \& Skov, 2014).

These results have inspired new ways of thinking about aesthetic appreciation (Chapter 7). Some researchers see in the neuroscientific results the indicators of neural activity that is specific to aesthetics (Ishizu \& Zeki, 2013; Kawabata \& Zeki, 2004). Conversely, others have argued that aesthetic appreciation does not involve specific brain regions or neural activity patterns, but the same networks as general sensory valuation (Skov, 2019; Skov \& Nadal, 2018). Somewhere in-between lie the positions of Vessel and colleagues (2012) and Chatterjee and Vartanian (2014). To Vessel and colleagues (2012), the key to aesthetic experiences is the integration of sensory and emotional brain signals through inward contemplation and self-referential processes, reflected in the increased activation of brain regions that integrate the default-mode network during intense aesthetic experiences. Chatterjee and Vartanian (2014) conceived aesthetic experiences as emergent states that arise from the interaction between neural systems involved in sensory-motor processes, emotion 
and valuation, and meaning and knowledge. They argued that, although the interactions between these systems is the same as in aesthetic and non-aesthetic interactions with objects, aesthetic experiences differ from non-aesthetic experiences in that the cognitive appraisals focus on the context in which the interaction takes place (like a museum or a concert hall) and the object and its features, rather than on the outcomes.

\section{Factors that influence aesthetics}

As noted above, the basic strategy for the generation of knowledge in Empirical Aesthetics is the empirical method. Studies of this kind begin with one or few theory-driven hypotheses that specify the expected correlative or causal relation between one or more causal factors, and one or more outcome variables. Depending on the goals and the nature of the study (e.g., observational, quasi-experimental, experimental), and on the causal factors and outcome variables specified by the hypotheses, researchers will use one or several methods to observe and measure responses. This section examines some of the basic causal factors that are commonly studied in Empirical Aesthetics, whereas the next section examines some of the most common measurement methods.

The basic factors that influence aesthetic appreciation can be grouped into three broad categories: those that have to do with the features of the object that is appreciated (Chapters in sections 3 and 4), those that have to do with the person who is doing the appreciating (Chapters in section 5), and those that have to do with the context in which the appreciation is taking place (Chapters in section 6) (see also Jacobsen, 2006). As it takes place in everyday life, aesthetic appreciation is brought about by interactions among factors of the three sorts. However, most studies in empirical aesthetics will study the effects of one of these factors, while exerting some kind and measure of control on the others. 


\subsection{Object features}

The object features that influence aesthetic appreciation vary from one sensory modality to another, and from one artform to the next. A comprehensive treatment of these is given in the chapters included in sections 3 and 4. Still, some general principles apply across sensory modalities and artforms. As we saw in section 2.5 , Berlyne $(1971,1974)$ showed that collative properties have a strong effect on aesthetic appreciation. According to Berlyne (1971), certain features of sound and visual patterns that vary in space and time contribute to the complexity, novelty, and surprisingness of musical compositions, landscapes, paintings, choreographies, poems, movies, and so on. He expected that people would generally prefer intermediate levels of complexity, in any of its visual and auditory forms (Chapter 18).

Fluency theory (Forster et al., 2013; Reber et al., 2004) is another example of a general principle that applies across modalities and media. As we saw in section 3.1., the theory posits that certain features of visual or auditory objects makes them easier or more difficult to process, and that people will prefer those that are experienced as easier (Chapter 19). Fluency theory encompasses Martindale's (Martindale, 1984; Martindale \& Moore, 1988) prototype theory because one of the features that makes objects easier to process is their typicality.

The features that contribute to complexity, novelty, surprise, variability and fluency are attributes of objects, such as the number of elements in a display or the figure ground contrast. However, collative properties and fluency are actually subjective, that is to say, they are attributes of people's experience of those objects (Berlyne, 1971, 1974; Forster et al., 2013). Nevertheless, the chapters on collative properties and fluency are included in Section 3 that focuses on object features for the practical reason that they are usually manipulated experimentally by adjusting object properties. 


\subsection{Personal features}

The main goal of Empirical Aesthetics has been to provide general explanations for the way features of objects shape the way people value them (Berlyne, 1971; Martindale, 1990; McManus \& Wu, 2013). Such explanations often rely on general perceptual, cognitive, and affective processes to account for regular and predictable responses to complexity, symmetry, balance, contour, and so on (Leder \& Nadal, 2014; Pelowski et al., 2017).

However, people differ substantially in what they like and prefer (Jacobsen, 2004; Jacobsen \& Höfel, 2002). Aesthetic appreciation, thus, is not merely a response to object features. Fechner (1866) believed that aesthetic appreciation was the result of the interaction and interweaving of two factors. One, the direct factor, referred to object properties, and the other, the association factor, referred to each person's knowledge, memories, and past experiences. Segal $(1905,1906)$ confirmed that object features alone could not account for aesthetic appreciation. He argued that aesthetic appreciation was not a response to object features, but people's thoughts and feelings about those features, and that these depended to a large extent on their personalities, moods, and dispositions.

Since those early experiments, a vast amount of evidence has accumulated on differences among people in their aesthetic preferences, especially for cultural products, such as art and architecture (Edward A. Vessel, Maurer, Denker, \& Starr, 2018). Such differences have been attributed to the effects of momentary deployments of cognitive resources, such as attention or working memory (Chapter 33), factors that change slowly throughout life, such as age (Chapter 34) and expertise (Chapter 35), and factors that remain relatively stable throughout life, such as personality (Chapter 36), aesthetic sensitivity (Chapter 37), and cultural background (Chapter 38).

This extensive knowledge of the effects of personal attributes shows how wrong it is to conceive aesthetic appreciation (liking, beauty, or attractiveness) as a direct and passive 
effect of object features. Aesthetic appreciation is an active process that is modulated by many personal attributes. However, this feature is not just true of aesthetic appreciation, but rather true of all human experience. Our experience of the world is not the result of passive reactions to events. We construct our experience of the world through active processes of perception ("Whether beautiful or ugly or just conveniently at hand, the world of experience is produced by the [person] who experiences it," (Neisser, 1967, p. 3), memory ("remembering appears to be far more decisively an affair of construction rather than one of mere reproduction," (Bartlett, 1932, p. 205), and emotion ("each emotional episode is constructed rather than triggered," (Barrett \& Russell, 2015, p. 4). The main goal of cognitive psychology was to "discover and to describe formally the meanings that human beings created out of their encounters with the world, and then to propose hypotheses about what meaning-making processes were implicated (Bruner, 1990, p. 2).

\subsection{Context features}

Human cognition does not take place in the void. Recent developments in cognitive psychology and neuroscience have shown that it relies to a considerable extent on the organizing resources present in the surrounding environment (Hutchins, 1995). These developments emphasize the situatedness of cognition, and the role of contextual constraints and affordances in perception, memory, and action (Barsalou, 2008; Clark, 1997; Hutchins, 1995; Smith \& Vela, 2001). From this perspective, "Mental events and human behaviors can be thought of as states that emerge from moment-by-moment interaction with the environment rather than proceeding in autonomous, invariant, context-free fashion from preformed predispositions or causes. Inherently, a mind exists in context" (Barrett, Mesquita, \& Smith, 2010, p. 5). 
Despite this reality, Empirical Aesthetics has traditionally conducted its studies in psychological or neuroimaging laboratories. These laboratories are designed intentionally to minimize the sort of contextual elements that contribute to shaping experiences in everyday environments, such as other people, sounds and smells, decorations, design furniture, and art (Mastandrea, Bartoli, \& Bove, 2009; Tschacher et al., 2012). In Art as Experience, Dewey (1934) highlighted the fundamental role of context in the experience of art: "Experience is a matter of the interaction of organism with its environment, an environment that is human as well as physical, that includes the materials of tradition and institutions as well as local surroundings" (Dewey, 1934, p. 256). But it was not until the 1990s that Empirical Aesthetics began systematically studying the effects of different contextual aspects on aesthetic experience (Chapters 39-43). Some of these studies examined the impact of art exhibition arrangement, artwork presentation, and the amount and kind of information on the behavior of museum visitors (Bitgood \& Patterson, 1993; Falk, 1993; Temme, 1992). Other studies examined the effects of information about the artworks, their titles, and the artists on aesthetic appreciation, looking time, and eye movement patterns (Belke, Leder, \& Augustin, 2006; Franklin, Becklen, \& Doyle, 1993; Hristova, Georgieva, \& Grinberg, 2011; Millis, 2001). Others attempted to determine whether presentation format has an impact on the evaluation of formal features of artworks and their appreciation (Locher, Smith, \& Smith, 2001; Locher, Smith, \& Smith, 1999). Only in the past decade have studies tested the effects of the actual physical context (laboratory, museum, or street) in which aesthetic appreciation takes place on outcome measures of interest (Brieber, Leder, \& Nadal, 2015; Brieber, Nadal, Leder, \& Rosenberg, 2014; Gartus \& Leder, 2014; Grüner, Specker, \& Leder, 2019). Together, these studies demonstrate that if "human cognition is always situated in a complex sociocultural world and cannot be unaffected by it" (Hutchins, 1995, p. xiii), then art is certainly no exception. 


\section{Measurement methods}

As noted above, the goals of each particular study determine the set of factors that are expected to cause or be associated with the set of outcomes, and the most suitable methods to measure these outcomes. These methods fall into four groups, depending on whether they measure historical data, verbal responses, nonverbal responses, or psychophysiological changes.

\subsection{Historiometric methods}

These methods allow researchers to quantitatively analyze historical data on samples of historical individuals, such as artists, or of historical objects, such as artworks, and their social and cultural environment (Simonton, 1990). The goal of these methods is to test hypotheses about factors surrounding individuals, objects, or movements, that have become of historical relevance (Chapter 9). The basic units of analysis range from specific creations to individuals and to entire movements and periods. Simonton (2018), for instance, used historiometric methods to study the circumstances that favor the alternations of golden ages, formed by clusters of highly creative individuals, and periods of relatively little creativity. Martindale (1990) analyzed different sorts of historical data, and showed that across many artforms and periods, a common pressure to attain novelty drives artists and movements to break with the rules.

\subsection{Verbal ratings and judgments}

This is, by far, the most commonly used method to analyze the outcomes of aesthetic appreciation (Berlyne, 1972, 1974). It requires participants to verbally express some aspect of the way they experience a stimulus. The most common aspects participants are asked to 
inform us about are descriptive aspects of the stimuli (such as their complexity, regularity, or novelty), evaluative aspects of the hedonic value (such as interestingness, pleasingness, liking, beauty, or attractiveness), and internal states (such as evoked emotions or meanings). There are many other different ways to collect verbal ratings and judgments. The most common ones are giving participants the choice among two possible alternatives (e.g., simple or complex, like or do not like), giving participants graded scales divided into several points that represent discrete degrees of their response (e.g., more or less complex, like more or less), or using continuous scales that represent all possible gradations of their response. These verbal measures are usually accompanied by measures of response times, under the assumption that they reflect something about the processing of the responses, such as task difficulty, response elaboration, or indecision. The particular aspect that is measured and the way it is measured are determined by, and should be in consonance with, each study's goals and hypotheses, especially when measures differ in their degree of sensitivity to the effects of certain factors (e.g., Palumbo \& Bertamini, 2016).

Verbal ratings and judgments are among the easiest measures of aesthetic appreciation to collect and analyze but, for several reasons, they are also among the most problematic. Verbal measurements have several weaknesses, especially when not combined with other forms of measurement. First, the vast majority of studies in Empirical Aesthetics have measured participants' verbal responses using Fechner's method of choice (Chapter 3). Thus, most of the knowledge in the field rests on variations upon a single method. Second, they are the result of introspection. Psychology rejected introspective methods early in the $20^{\text {th }}$ century for good reasons: it is unclear how accurate people are when they access their own psychological processes and states, and their responses are easily and unwillingly influenced by undesired factors, such as expectations, social desirability, and other demand characteristics of the study. Third, participants' verbal responses will reflect their 
understanding of the instructions and scales. Descriptive terms such as complex or simple, and descriptive terms such as liking, beauty and attractiveness, can mean different things to different participants, and participants differ in the way they use them in reference to the rated or judged objects.

One way to avoid these problems would be to dispense with measuring verbal responses entirely. But, for several reasons, this might be an excessively radical and undesirable solution. First, verbal ratings and judgments are a rich source of information about aesthetic appreciation. Second, they often produce results that correlate with those of non-verbal measurements (Berlyne, 1972). For instance, verbal measures of preference for curvature (i.e., people generally rate curved shapes as more pleasing and likable than angular shapes) are supported by several forms of nonverbal measures that indicate that people find curved shapes more approachable (Bertamini, Palumbo, Gheorghes, \& Galatsidas, 2016). Third, not all verbal measures require participants to introspect about their responses. There are several kinds of tasks that measure participants' implicit attitudes toward or associations between objects, situations or values (Chapter 12). For instance, Palumbo and colleagues (2015) used implicit measures to show that participants associated curved shapes with positive and safe concepts, and angular shapes with negative and threatening concepts. Fourth, several valid and reliable methods exist for the analysis and interpretation of declarative self-report data that can shed light on the mechanics of thought, such as thinkaloud protocols. Thus, rather than discarding verbal measures, it is better to design experiments that control for the kinds of extraneous influences they are sensitive to, and to combine them with nonverbal, implicit, or physiological measures.

\subsection{Measurement of nonverbal behavior}


Berlyne $(1972,1974)$ classified behavioral measures into measures of exploration choice and measure of exploration time. Measures of exploration choice quantify the frequency with participants choose to expose themselves to different alternative objects (Chapter 10). In the laboratory, this procedure usually involves initially presenting the alternatives to participants, giving them the chance of choosing among the alternatives for additional presentations, and measuring the frequency of choices. In the field, such as in museums or in parks, this procedure usually requires researchers to record the objects, among all the alternatives, visitors choose to engage with (Mitschke, Goller, \& Leder, 2017). Measures of exploration time quantify the time participants choose to spend engaged with different alternative objects. Brieber and colleagues (2014), for instance, measured the time participants chose to view artworks in the laboratory and in a museum, and found a relation between the chosen viewing time and how much participants liked the artworks. Hayden and colleagues (2007) measured the relation between attractiveness, viewing time and cost, and found that people are willing to pay more and work harder to spend time viewing images of attractive people of the opposite sex than of less attractive people.

Eye movements constitute an especially interesting form of exploratory behavior for Empirical Aesthetics. Eye tracking methods allow the simultaneous measurement of exploratory behavior, in the form of the regions of an image that participants choose to explore in more or less detail, and of exploratory time, in the form of the duration of fixations at a given location. Many studies have shown that the factors that influence aesthetic appreciation also influence the locations participants focus on, the time they spend at each location, and the path from one location to another (Chapter 13).

\subsection{Psychophysiological measures}


Empirical Aesthetics has benefited greatly from improvements to the precision and reliability of the instruments to measure psychophysiological parameters, advances in the computer software for analyzing psychophysiological data, reductions in the expense of these systems, and the development of mobile devices that can be used outside of the laboratory. Studies that make use of these measures, most often in combination with verbal or nonverbal behavioral measures, are becoming more and more common. Researchers have studied the physiological components of aesthetic appreciation using peripheral measurements, such as skin conductance, facial muscle contractions, pupillary dilation, and measurements or transient alterations of brain activity using electroencephalography, magnetoencephalography, functional resonance magnetic imaging, and brain stimulation (Chapters 14-16). The field is also on the verge of incorporating interoceptive measures to its methodological stock, which will show the relation between aesthetic appreciation and signals from different organs of our respiratory, cardiac, and digestive systems.

\section{Subdomains of Empirical Aesthetics}

Although, as we have seen, Empirical Aesthetics began as a branch of experimental psychology, in its 150 years of history it has been enriched by the addition of different perspectives (Seeley, 2014a). Today, Empirical Aesthetics is multidisciplinary endeavor, and can be regarded as the intersection of the empirical facets of different scientific approaches to aesthetics: psychological aesthetics, neuroaesthetics, evolutionary aesthetics, environmental aesthetics, psychometric aesthetics, computational aesthetics, and medical aesthetics (Figure 1). 


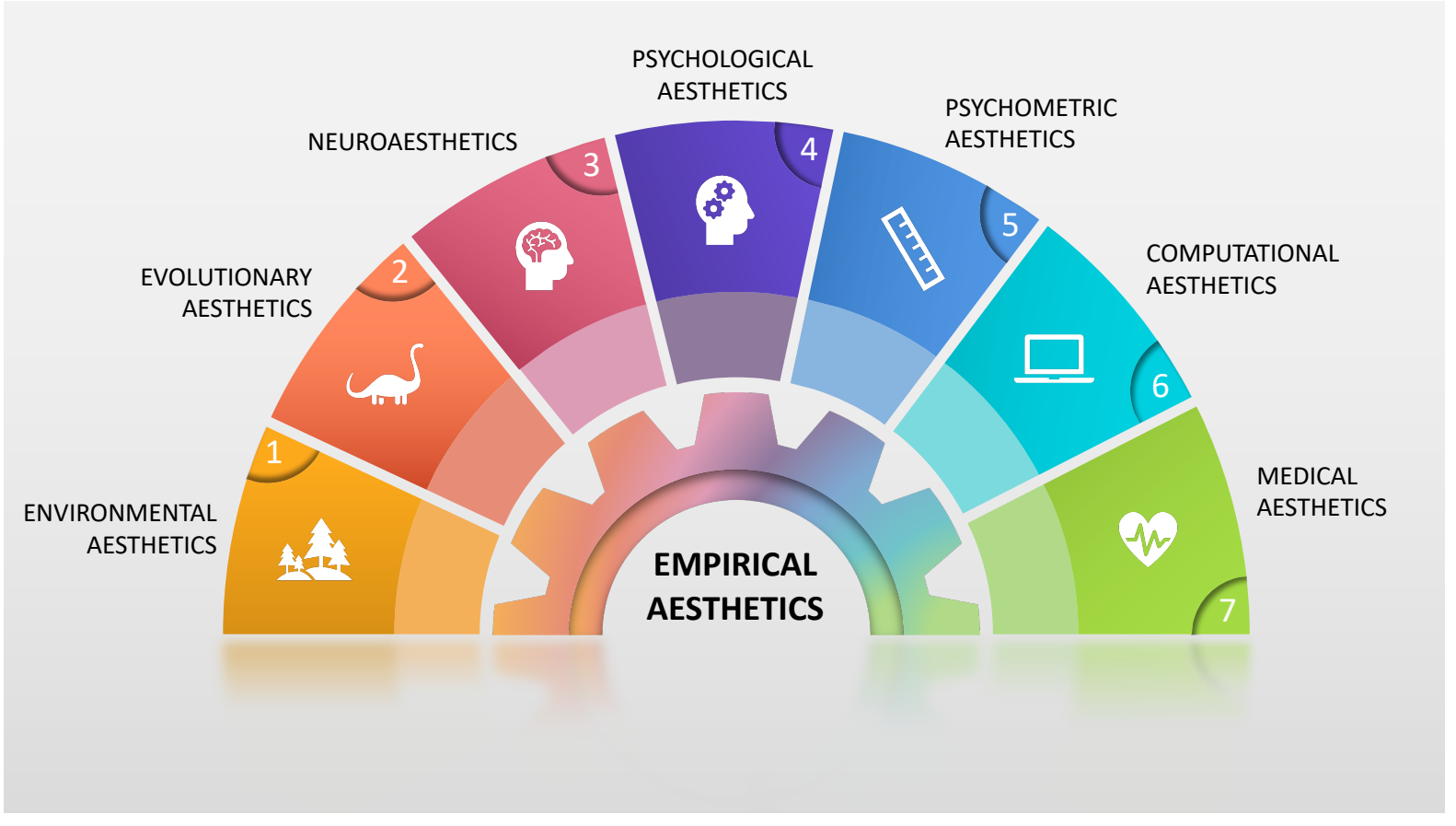

Figure 1: Subdomains of Empirical Aesthetics. Empirical Aesthetics can be understood as the intersection of the empirical facets of Environmental Aesthetics, Evolutionary Aesthetics, Neuroaesthetics, Psychological Aesthetics, Psychometric Aesthetics, Computational Aesthetics, and Medical Aesthetics.

- Psychological aesthetics is the oldest of these domains, as it corresponds with Fechner's $(1871,1876)$ notion of experimental aesthetics. Its main goal is to understand the psychological processes involved in aesthetic appreciation and creation, as well as its psychological consequences. Arnheim's Gestalt perspective and Leder and colleagues' (2004) information processing model were crucial contributions to psychological aesthetics. An example of empirical research in this domain is Brielman and Pelli's (2017)'s use of cognitive load manipulations to demonstrate that appreciating beauty entails the participation of executive functions.

- Neuroaesthetics is one of the most recent additions to the domains of Empirical Aesthetics. Zeki (1999) coined the term and argued that knowledge about visual processing in the brain could explain how the different features of artworks, such as 
color or movement, achieved their appealing effects. The first empirical studies on the neural underpinnings of aesthetic appreciation soon followed (Cela-Conde et al., 2004; Jacobsen \& Höfel, 2001; Kawabata \& Zeki, 2004; Vartanian \& Goel, 2004). Calvo-Merino and colleagues' $(2010 ; 2007)$ studies showing that the aesthetic appreciation of dance engages brain systems related to the representation of movement illustrate the sort of work in this domain.

- Evolutionary aesthetics applies the principles and methods of evolutionary biology to the problems of aesthetics. Its goal is to explain the origins and evolution of aesthetic appreciation and creation as the result of natural and sexual selection (Gangestad \& Scheyd, 2005; Prum, 2017; Voland \& Grammer, 2003; Zaidel, Nadal, Flexas, \& Enric, 2013). Given that most work in this domain assumes that art and aesthetics constitute adaptations, that is to say, traits that increased the chances for survival and reproduction to their possessors, one of the fundamental questions concerns the adaptive advantages conferred by art and aesthetics. There are many examples of empirical work in this domain that show a close relation between aesthetics and signals of health, social and sexual status (Fink, Grammer, \& Matts, 2006; Skamel, 2003). Although these studies have traditionally focused on the signals and the signaler, the interest is currently shifting toward the complex processes involved in the valuation of those signals (Achorn \& Rosenthal, 2020), and the way these valuation mechanisms exploit pre-existing sensory biases in the choosers' sensory system (Ryan, 2018).

- Environmental aesthetics seeks to understand the factors that modulate people's aesthetic responses to natural and urban environments (Kaplan, 1992; Ulrich, 1977). Some of the most striking work has been conducted on the effects on wellness and stress reduction of certain features of natural environments (Ulrich, 1991; Ulrich et 
al., 1991) and interior architectural spaces (Fich et al., 2014). A classic example of the kind of research conducted in this domain is Balling and Falk's (1982) study showing that children prefer savannah-type landscapes over other kinds of landscapes, but that as people grow up they tend to prefer familiar kinds of landscapes just as much, which they interpreted as evidence for an innate preparedness to prefer savanna-like environments.

- Psychometric aesthetics is a broad domain that aims to develop adequate instruments for the measurement of art and aesthetic appreciation, talent, and knowledge. The domain grew out of early interest in quantifying group norms and variations (Thorndike, 1916, 1917), and of the early visual art and music aptitude tests (Meier \& Seashore, 1929). Myszkowski and colleagues' (2018; 2017)'s recent studies on the Visual Aesthetic Sensitivity Scale are good illustrations of the kind of empirical work conducted in this domain.

- Computational Aesthetics develops mathematical models of choices in aesthetic appreciation and creation based on the principles that underlie aesthetic forms (Emch, 1900; Greenfield \& Machado, 2012; Hoenig, 2005). Schmidhuber (2006) developed artificial agents that simulate scientists and artists in their curiosity and creativity. The agents incorporate two learning systems: a model of the agent's history of interaction with the environment, and a reinforcement learner, which selects new actions. This reinforcement learner is motivated to invent new and interesting things, and it does so by choosing increasingly complex and unpredictable patterns. Other fully automated systems have been developed to combine an automatic art critic architecture and a genetic programming engine. These combinations used evolutionary computation to generate images that a neural network can discriminate and classify. The iterative process leads to the refinement 
of the network's function and drives the evolutionary algorithm to explore new paths (Machado, Romero, Cardoso, \& Santos, 2005; Machado, Romero, \& Manaris, 2008). Some of the most recent developments in computational aesthetics involve neural networks that are able to predict humans' aesthetic judgments, suggest enhancements to the aesthetic quality of images, and even imitate art styles (Schwarz, Wieschollek, \& Lensch, 2018; Talebi \& Milanfar, 2018).

- Medical aesthetics is mostly concerned with the relation between physical appearance and its health and wellbeing consequences. Its interventions usually involve reconstructive surgery due to traumatic injury or skin diseases, cosmetic surgery, and dental implants. Studies on the psychological causes and consequences of satisfaction with cosmetic surgery are illustrative examples of empirical work in this domain (Brunton et al., 2014; Herruer, Prins, van Heerbeek, Verhage-Damen, \& Ingels, 2015; von Soest, Kvalem, Roald, \& Skolleborg, 2009).

Some of the future challenges facing Empirical Aesthetics concern its constituting domains. Anglada-Tort and Skov (2020) have shown that whereas some of these domains share a common understanding of important concepts and that knowledge generated in one is used in the other, as is the case with neuroaesthetics and psychological aesthetics, other domains seem to have their own understanding of central concepts and share little knowledge with the rest of domains, as is the case with computational aesthetics and medical aesthetics, for instance. There is still much to be done in the way of integration, and much to be gained too. Another challenge for the future of Empirical Aesthetics is adding further domains. Empirical Aesthetics would benefit enormously from a domain on comparative aesthetics (Westphal-Fitch \& Fitch, 2015) and a domain on genetic aesthetics. Although the literature on animal visual and auditory preferences is vast, it is largely unconsidered by Empirical 
Aesthetics, and very few studies have directly compared aesthetic preferences of humans an nonhuman animals (Mühlenbeck, Liebal, Pritsch, \& Jacobsen, 2015; Mühlenbeck, Jacobsen, Pritsch, \& Liebal, 2017; Mühlenbeck, Liebal, Pritsch, \& Jacobsen, 2016; Munar, GomezPuerto, Call, \& Nadal, 2015). Genetic aesthetics is one of the most promising and unexplored possibilities for Empirical Aesthetics. It is therefore encouraging to see the first steps in this direction, with a study that shows that variation in the intensity of aesthetic experience owes partly to genetic factors (Bignardi, Ticini, Smit, \& Polderman, 2020).

\section{Ties with neighboring fields, past and future}

Empirical Aesthetics feeds from and contributes to other fields in the behavioral and brain sciences that provide concepts and methods to study cognition and its neural underpinnings, and other fields in the humanities and biology that study different aspects of art and aesthetics.

Empirical Aesthetics is tied to other fields of the behavioral and brain sciences because the appreciation and creation of art and aesthetics is the product of fundamental features of brain structure and function. As such, they are governed by the same psychological and neurobiological principles as any other human activity (Berlyne, 1971; Skov \& Nadal, 2018). The importance of these general principles for Empirical Aesthetics cannot be overstated: "There can be no understanding of art without bringing art into relation with non-artistic forms of behavior" (Berlyne, 1971, p. 26). Transformative progress in Empirical Aesthetics has always been the result of strengthening the ties with other domains of psychology and neuroscience: Fechner (1871) founded the domain by using psychophysical methods to establish it, Arnheim (1974) applied the Gestalt principles to the appreciation of art, and Berlyne (1971) used general motivational and information theory principles to aesthetic appreciation, and neuroaesthetics emerged when the methods and 
concepts of neuroscience were used to ask questions about neuroaesthetics (Chatterjee, 2011; Nadal \& Pearce, 2011).

Among the domains of the behavioral and brain sciences, Empirical Aesthetics has intersected most often with personality psychology, social psychology, consumer psychology, affective neuroscience, neuroeconomics, and social neuroscience. In the future, this list could be expanded to include other fields, such as cognitive engineering, to study how aesthetic features can improve the design of human-machine interfaces, physiology, to study the role of interoceptive signals participate in aesthetic appreciation, and neurogenomics, to study the relation between genetic expression in neural tissue and aesthetic appreciation, and neuroethics, to better understand the moral and societal implications of facial and aesthetic deformities on judgment.

Part of what makes aesthetics such a fascinating topic is the many angles from which it can be approached. No single approach-Empirical Aesthetics included — can hope to provide a complete picture of the many facets of art and aesthetics. George Santayana (1904) realized this when discussing the place of aesthetics in relation to psychology: "the question whether aesthetics is a part of psychology or a separate discipline is (...) an insoluble question, because it creates a dilemma which does not exist in the facts. A part of psychology deals with aesthetic matters, but cannot exhaust them; parts of other sciences also deal with the same. A single and complete aesthetic science, natural or ideal, is an idol of the cave and a scholastic chimera" (Santayana, 1904, p. 327). This is just as true today as it was a century ago.

A comprehensive understanding of aesthetics can only emerge from the dialogue between neighboring fields that approach it from different angles. For instance, for several decades, Empirical Aesthetics has had a very fruitful relation with the field of design (Erk, Spitzer, Wunderlich, Galley, \& Walter, 2002; Ho, Lu, \& Chen, 2016; Schaefer \& Rotte, 
2007), and we are currently witnessing the beginning of what seems will be a fascinating interaction between Empirical Aesthetics and architecture (Eberhard, 2009; Goldstein, 2006; Graham, Gosling, \& Travis, 2015; Sternberg \& Wilson, 2006).

The relation between Empirical Aesthetics and some of the humanities, however, have not always been as fruitful as could be hoped for (Chapters 4 and 5). Nevertheless, despite important conceptual and methodological differences between empirical and philosophical aesthetics, it has been shown that there are plenty of reasons and grounds for rapprochement between philosophical and empirical aesthetics (Hayn-Leichsenring \& Chatterjee, 2019; Seeley, 2006, 2011, 2014b). The same is true for the interaction between empirical aesthetics and art theory and art history (Bullot \& Reber, 2013; Kozbelt \& Seeley, 2007), a collaboration that has already proved to be extremely fruitful when common goals are set (Brinkmann, Commare, Leder, \& Rosenberg, 2014; Leder et al., 2019). There is great potential in the future for Empirical Aesthetics if it can establish significant links with the fields of human evolution and sexual selection, to study the geometric patterns and decorations created by our evolutionary ancestors and the similarities between human preferences and animal displays and mate choice (Skov, 2020).

\section{Acknowledgements}

We would like to thank Aenne Brielmann and Giacomo Bignardi for helpful comments that substantially improved this chapter. 


\section{References}

Achorn, A. M., \& Rosenthal, G. G. (2020). It's Not about Him: Mismeasuring "Good Genes" in Sexual Selection. Trends in Ecology \& Evolution, 35(3), 206-219. https://doi.org/10.1016/j.tree.2019.11.007

Adler, M. J. (1929). Music appreciation: an experimental approach to its measurement. Archives of Psychology, 110, 1-102.

Allesch, G. J. v. (1925). Die ästhetische Erscheinungsweise der Farben. Psychologische Forschung, 6(1), 1-91. https://doi.org/10.1007/BF00444162

Anglada-Tort, M., \& Skov, M. (2020). What counts as Aesthetics in Science? A Bibliometric Analysis and Visualization of the Scientific Literature from 1970 to 2018.

Arnheim, R. (1964). Art and Visual Perception. Berkeley, CA: University of California Press.

Arnheim, R. (1966). Toward a psychology of art. Berkeley, CA: The University of California Press.

Arnheim, R. (1969). Visual Thinking. Berkeley, CA: University of California Press.

Arnheim, R. (1974). Art and visual perception. A psychology of the creative eye. The new version. Berkeley, CA: The University of California Press.

Balling, J. D., \& Falk, J. H. (1982). Development of visual preference for natural environments. Environment and Behavior, 14, 5-28.

Bar, M. (2004). Visual objects in context. Nature Reviews Neuroscience, 5, 617-629.

Barnhart, E. N. (1940). The Criteria Used in Preferential Judgments of Geometrical Forms. The American Journal of Psychology, 53, 354-370.

Barrett, L. F., Mesquita, B., \& Smith, E. R. (2010). The context principle. In B. Mesquita, L. F. Barrett, \& E. R. Smith (Eds.), The mind in context (pp. 1-22). New York: The Guilford Press. 
Barrett, L. F., \& Russell, J. A. (2015). The psychological construction of emotion. New York, NY: The Guilford Press.

Barron, F., \& Welsh, G. S. (1952). Artistic perception as a possible factor in personality style: Its measurement by a figure preference test. The Journal of Psychology, 33, 199203.

Barsalou, L. W. (2008). Grounded cognition. Annual Review of Psychology, 59, 617-645.

Bartlett, F. C. (1932). Remembering. A study in experimental and social psychology. Cambridge : Cambridge University Press.

Belke, B., Leder, H., \& Augustin, D. (2006). Mastering style - Effects of explicit stylerelated information, art knowledge and affective state on appreciation of abstract paintings. Psychology Science, 48, 115-134.

Berlyne, D. E. (1971). Aesthetics and Psychobiology. New York: Appleton-Century-Crofts.

Berlyne, D. E. (1972). Ends and means of experimental aesthetics. Canadian Journal of Psychology, 26(303-325).

Berlyne, D. E. (1974). The new experimental aesthetics. In D. E. Berlyne (Ed.), Studies in the new experimental aesthetics: Steps toward an objective psychology of aesthetic appreciation (pp. 1-26). Washington, D. C.: Hemisphere Publishing Corporation.

Bertamini, M., Palumbo, L., Gheorghes, T. N., \& Galatsidas, M. (2016). Do observers like curvature or do they dislike angularity? British Journal of Psychology, 107, 154-178.

Bignardi, G., Ticini, L. F., Smit, D., \& Polderman, T. J. (2020). Domain-Specific and Domain-General Genetic and Environmental Effects on the Intensity of Visual Aesthetic Appraisal. https://doi.org/10.31234/osf.io/79nbq

Bitgood, S., \& Patterson, D. D. (1993). The effects of gallery changes on visitor reading and object viewing time. Environment and Behavior, 25, 761-781.

Brieber, D., Leder, H., \& Nadal, M. (2015). The experience of art in museums: An attempt to 
dissociate the role of physical context and genuineness. Empirical Studies of the Arts, 33(1). https://doi.org/10.1177/0276237415570000

Brieber, D., Nadal, M., Leder, H., \& Rosenberg, R. (2014). Art in time and space: Context modulates the relation between art experience and viewing time. PLoS ONE, 9(6). https://doi.org/10.1371/journal.pone.0099019

Brielmann, A. A., \& Pelli, D. G. (2017). Beauty requires thought. Current Biology, 27, 15061513.

Brighouse, G. (1939a). A study of aesthetic apperception. Psychological Monographs, 51, 122.

Brighouse, G. (1939b). Variability in preference for simple forms. Psychological Monographs, 51, 68-74.

Brinkmann, H., Commare, L., Leder, H., \& Rosenberg, R. (2014). Abstract art as a universal language? Leonardo, 47, 256-257.

Brown, S., Gao, X., Tisdelle, L., Eickhoff, \& Liotti, M. (2011). Naturalizing aesthetics: Brain areas for aesthetic appraisal across sensory modalities. NeuroImage, 58, 250-258.

Bruner, J. (1990). Acts of meaning. Cambridge, MA: Harvard University Press.

Brunton, G., Paraskeva, N., Caird, J., Bird, K. S., Kavanagh, J., Kwan, I., ... Thomas, J.

(2014). Psychosocial Predictors, Assessment, and Outcomes of Cosmetic Procedures: A Systematic Rapid Evidence Assessment. Aesthetic Plastic Surgery, 38(5), 1030-1040. https://doi.org/10.1007/s00266-014-0369-4

Bullot, N. J., \& Reber, R. (2013). The artful mind meets art history: toward a psychohistorical framework for the science of art appreciation. Behavioral and Brain Sciences, $36,123-137$.

Cahalan, E. J. (1939). The consistency of aesthetic judgment. Psychological Monographs, 51, 75-87. https://doi.org/10.1037/h0093478 
Calvo-Merino, B., Urgesi, C., Orgs, G., Aglioti, S. M., \& Haggard, P. (2010). Extrastriate body area underlies aesthetic evaluation of body stimuli. Experimental Brain Research, 204, 447-456.

Carroll, H. A. (1933). What Do the Meier-Seashore and the McAdory Art Tests Measure? The Journal of Educational Research, 26, 661-665.

Cela-Conde, C. J., Marty, G., Maestú, F., Ortiz, T., Munar, E., Fernández, A., ... Quesney, F. (2004). Activation of the prefrontal cortex in the human visual aesthetic perception. Proceedings of the National Academy of Sciences USA, 101, 6321-6325.

Chan, J., Eysenck, H. J., \& Götz, K. O. (1980). A new visual aesthetic sensitivity test: III Cross-cultural comparison between Hong Kong children and adults, and English and Japanese samples. Perceptual and Motor Skills, 50, 1325-1326.

Chatterjee, A. (2004). The neuropsychology of visual artistic production. Neuropsychologia, $42,1568-1583$.

Chatterjee, A. (2006). The neuropsychology of visual art: Conferring capacity. International Review of Neurobiology, 74, 39-49.

Chatterjee, A. (2011). Neuroaesthetics: A coming of age story. Journal of Cognitive Neuroscience, 23, 53-62.

Chatterjee, A. (2014). Scientific aesthetics: Three steps forward. British Journal of Psychology, 105, 465-467.

Chatterjee, A., \& Vartanian, O. (2014). Neuroaesthetics. Trends in Cognitive Sciences, 18, $370-375$.

Christensen, J. F. (2017). Pleasure junkies all around! Why it matters and why 'the arts' might be the answer: a biopsychological perspective. Proceedings of the Royal Society B: Biological Sciences, 284(1854), 20162837. https://doi.org/10.1098/rspb.2016.2837

Chuan-Peng, H., Huang, Y., Eickhoff, S. B., Peng, K., \& Sui, J. (2020). Seeking the "Beauty 
Center" in the Brain: A Meta-Analysis of fMRI Studies of Beautiful Human Faces and Visual Art. Cognitive, Affective, \& Behavioral Neuroscience, in press.

https://doi.org/10.3758/s13415-020-00827-z

Clair, M. B. (1939). Variation in the perception of aesthetic qualities in paintings.

Psychological Monographs, 51(5), 52-67.

Clark, A. (1997). Being there. Putting brain, body, and world together again. Cambridge, MA: MIT Press.

Clark, H., Quackenbush, N., \& Washburn, M. F. (1913). A suggested coefficient of affective sensitiveness. The American Journal of Psychology, 24, 583-585.

Davis, F. C. (1933). Aesthetic proportion. The American Journal of Psychology, 45, 298302.

Dayan, P., \& Abbott, L. F. (2001). Theoretical Neuroscience. Computational and Mathematical Modeling of Neural Systems. Cambridge, MA: The MIT Press.

Dewey, J. (1934). Art as experience. New York: Minton, Balch \& Company.

Eberhard, J. P. (2009). Applying neuroscience to architecture. Neuron, 62, 753-756.

Edmonds, E. M., \& Smith, M. E. (1923). The Phenomenological Description of Musical Intervals. The American Journal of Psychology, 287-291. https://doi.org/10.2307/1413583

Emch, A. (1900). Mathematical principles of esthetic forms. The Monist, 11, 50-64.

Erk, S., Spitzer, M., Wunderlich, A. P., Galley, L., \& Walter, H. (2002). Cultural objects modulate reward circuitry. NeuroReport, 13, 2499-2503.

Eysenck, H. J. (1941a). A critical and experimental study of colour preferences. American Journal of Psychology, 54, 385-394.

Eysenck, H. J. (1941b). The empirical determination of an aesthetic formula. Psychological Review, 48, 83-92. 
Eysenck, H. J. (1942). The experimental study of the "Good Gestalt" - A new approach. Psychological Review, 49, 344-363.

Eysenck, H. J. (1981). Aesthetic preferences and individual differences. In D. O’Hare (Ed.), Psychology and the arts (pp. 76-101). Sussex: The Harvester Press.

Falk, J. H. (1993). Assessing the impact of exhibit arrangement on visitor behavior and learning. Curator, 133-146.

Farnsworth, P. R. (1925). Atonic Endings in Melodies. The American Journal of Psychology, 394-400. https://doi.org/10.2307/1414163

Farnsworth, P. R. (1926a). Ending preferences among the three positions of the tonic chord. Journal of Comparative Psychology, 6, 95-102. https://doi.org/10.1037/h0072802

Farnsworth, P. R. (1926b). The Effect of Repetition on Ending Preferences in Melodies. The American Journal of Psychology, 37, 116-122.

Farnsworth, P. R. (1931). An historical, critical and experimental study of the SeashoreKwalwasser test battery. Genetic Psychology Monographs, 291-393.

Farnsworth, P. R. (1932). Preferences for rectangles. Journal of General Psychology, 7, 479481. https://doi.org/10.1080/00221309.1932.9918480

Fechner, G. T. (1860). Elemente der Psychophysik. Leipzig: Breitkopf und Härtel.

Fechner, G. T. (1866). Das Associationsprincip in der Aesthetik. Zeitschrift Für Bildende Kunst, 1, 179-191.

Fechner, G. T. (1871). Zur experimentalen Aesthetik. Leipzig: Hirzel.

Fechner, G. T. (1876). Vorschule der Ästhetik. Leipzig: Breitkopf und Härtel.

Fich, L. B., Jönsson, P., Kirkegaard, P. H., Wallergård, M., Garde, A. H., \& Hansen, A. (2014). Can architectural design alter the physiological reaction to psychosocial stress? A virtual TSST experiment. Physiology \& Behavior, 135, 91-97.

Fingerhut, J., \& Prinz, J. J. (2020). Aesthetic Emotions Reconsidered. The Monist, 103, 223- 
239.

Fink, B., Grammer, K., \& Matts, P. J. (2006). Visible skin color distribution plays a role in the perception of age, attractiveness, and health in female faces. Evolution and Human Behavior, 27, 433-442.

Forster, M., Leder, H., \& Ansorge, U. (2013). It felt fluent, and I liked it: Subjective feeling of fluency rather than objective fluency determines liking. Emotion, 13, 280-289. https://doi.org/10.1037/a0030115

Forster, M., Leder, H., \& Ansorge, U. (2016). Exploring the subjective feeling of fluency. Experimental Psychology, 63, 45-58. https://doi.org/10.1027/1618-3169/a000311

Franklin, M. B., Becklen, R. C., \& Doyle, C. L. (1993). The influence of titles on how paintings are seen. Leonardo, 26, 103-108.

Gangestad, S. W., \& Scheyd, G. J. (2005). The evolution of human physical attractiveness. Annual Review of Anthropology, 34(1), 523-548.

https://doi.org/10.1146/annurev.anthro.33.070203.143733

Garth, T. R. (1924). A Color Preference Scale for One Thousand White Children. Journal of Experimental Psychology, 7, 233-241.

Garth, T. R., \& Collado, I. R. (1929). The color preferences of Filipino children. Journal of Comparative Psychology, 9, 397-404.

Gartus, A., \& Leder, H. (2014). The white cube of the museum versus the gray cube of the street: The role of context in aesthetic evaluations. Psychology of Aesthetics, Creativity, and the Arts, 8, 311-320.

Geissler, L. R. (1917). The affective tone of color-combinations. In Studies in Psychology (pp. 150-174). Worcester, MA: Louis N. Wilson.

Goldstein, R. N. (2006). Architectural design and the collaborative research environment. Cell, 127, 243-246. 
Götz, K. O., Borisy, A. R., Lynn, R., \& Eysenck, H. J. (1979). A new visual aesthetic sensitivity test: I Construction and psychometric properties. Perceptual and Motor Skills, 49, 795-802.

Graf, L. K., \& Landwehr, J. R. (2015). A dual-process perspective on fluency-based aesthetics: the pleasure-interest model of aesthetic liking. Personality and Social Psychology Review, 19, 395-410.

Graf, L. K. M., \& Landwehr, J. R. (2017). Aesthetic Pleasure versus Aesthetic Interest: The Two Routes to Aesthetic Liking. Frontiers in Psychology, 8, 15. https://doi.org/10.3389/fpsyg.2017.00015

Graham, L. T., Gosling, S. D., \& Travis, C. K. (2015). The psychology of home environments: A call for research on residential space. Perspectives on Psychological Science, 10, 346-356.

Graves, M. (1948). Design Judgement Test. San Antonio: Psychological Corporation.

Greenfield, G., \& Machado, P. (2012). Guest editors' introduction. Journal of Mathematics and the Arts, 6, 59-64.

Grüner, S., Specker, E., \& Leder, H. (2019). Effects of context and genuineness in the experience of art. Empirical Studies of the Arts, 37, 138-152. https://doi.org/10.1177/0276237418822896

Guernsey, M. (1928). The Rôle of Consonance and Dissonance in Music. The American Journal of Psychology, 40, 173-204.

Guilford, J. P., \& Guilford, R. B. (1931). A prognostic test for students in design. Journal of Applied Psychology, 335-345. https://doi.org/10.1037/h0069952

Hayden, B. Y., Parikh, P. C., Deaner, R. O., \& Platt, M. L. (2007). Economic principles motivating social attention in humans. Proceedings of the Royal Society B: Biological Sciences, 274(1619), 1751-1756. https://doi.org/10.1098/rspb.2007.0368 
Hayn-Leichsenring, G. U., \& Chatterjee, A. (2019). Colliding terminological systemsImmanuel Kant and contemporary Empirical Aesthetics. Empirical Studies of the Arts, 37, 197-219. https://doi.org/https://doi.org/10.1177/0276237418818635

Heinlein, C. P. (1925). An experimental study of the Seashore Consonance Test. Journal of Experimental Psychology, 8, 408-433.

Heinlein, C. P. (1928). The affective characters of the major and minor modes in music. Journal of Comparative Psychology, 8, 101-142.

Herruer, J. M., Prins, J. B., van Heerbeek, N., Verhage-Damen, G. W. J. A., \& Ingels, K. J. A. O. (2015). Negative Predictors for Satisfaction in Patients Seeking Facial Cosmetic Surgery: A Systematic Review. Plastic and Reconstructive Surgery, 135(6). Retrieved from

https://journals.lww.com/plasreconsurg/Fulltext/2015/06000/Negative_Predictors_for_S atisfaction_in_Patients.15.aspx

Hevner, K. (1935a). Experimental studies of the affective value of colors and lines. Journal of Applied Psychology, 19, 385-398.

Hevner, K. (1935b). The Affective Character of the Major and Minor Modes in Music. The American Journal of Psychology, 47, 103-118.

Hevner, K. (1936). Experimental Studies of the Elements of Expression in Music. The American Journal of Psychology, 48, 246-268.

Hevner, K., \& Mueller, J. H. (1939). The effectiveness of various types of art appreciation aids. Journal of Abnormal and Social Psychology, 34, 63-72. https://doi.org/10.1037/h0059214

Ho, C.-H., Lu, Y.-N., \& Chen, C.-H. (2016). Influence of curvature and expertise on aesthetic preferences for mobile device designs. International Journal of Design, 10, 17-25.

Hoenig, F. (2005). Defining Computational Aesthetics. In L. Neumann, M. Sbert, B. Gooch, 
\& W. Purgathofer (Eds.), Proceedings of the First Eurographics conference on

Computational Aesthetics in Graphics, Visualization and Imaging (pp. 13-18). Aire-la-

Ville, Switzerland: The Eurographics Association.

Hristova, E., Georgieva, S., \& Grinberg, M. (2011). Top-Down Influences on Eye-

Movements during Painting Perception: The Effect of Task and Titles. In A. Esposito,

A. M. Esposito, R. Martone, V. Müller, \& G. Scarpetta (Eds.), Toward Autonomous, Adaptive, and Context-Aware Multimodal Interfaces. Theoretical and Practical Issues (pp. 104-115). Berlin: Springer-Verlag.

Hutchins, E. (1995). Cognition in the wild. Cambridge, MA: The MIT Press.

Ishizu, T., \& Zeki, S. (2013). The brain's specialized systems for aesthetic and perceptual judgment. European Journal of Neuroscience, 37, 1413-1420.

Israeli, N. (1928). Affective reactions to painting reproductions. A study in the psychology of aesthetics. Journal of Applied Psychology, 12, 125-139.

Iwawaki, S., Eysenck, H. J., \& Götz, K. O. (1979). A new visual aesthetic sensitivity test (VAST): II. Cross-cultural comparison between England and Japan. Perceptual and Motor Skills, 49, 859-862.

Jacobsen, T. (2004). Individual and group modelling of aesthetic judgment strategies. British Journal of Psychology, 95, 41-56.

Jacobsen, T. (2006). Bridging the arts and sciences: A framework for the Psychology of Aesthetics. Leonardo, 39, 155-162.

Jacobsen, T., \& Höfel, L. (2001). Aesthetics electrified: An analysis of descriptive symmetry and evaluative aesthetic judgment processes using event-related brain potentials. Empirical Studies of the Arts, 19, 177-190.

Jacobsen, T., \& Höfel, L. (2002). Aesthetic judgments of novel graphic patterns: Analyses of individual judgments. Perceptual and Motor Skills, 95, 755-766. 
Jacoby, L. L., Kelley, C. M., \& Dywan, J. (1989). Memory attributions. In H. L. Roediger III \& F. I. M. Craik (Eds.), Varieties of memory and consciousness: Essays in honour of Endel Tulving (pp. 391-422). Hillsdale, NJ: Lawrence Erlbaum.

Kaplan, S. (1992). Environmental preference in a knowledge-seeking, knowledge-using organism. In J. H. Barkow, L. Cosmides, \& J. Tooby (Eds.), The Adapted Mind: Evolutionary Psychology and the Generation of Culture (pp. 581-598). New York, NY: Oxford University Press.

Katz, S. E., \& Breed, F. S. (1922). Color preferences of children. Journal of Applied Psychology, 6, 255-266.

Kawabata, H., \& Zeki, S. (2004). Neural Correlates of Beauty. Journal of Neurophysiology, $91,1699-1705$.

Kozbelt, A., \& Seeley, W. P. (2007). Integrating Art Historical, Psychological, and Neuroscientific Explanations of Artists' Advantages in Drawing and Perception. Psychology of Aesthetics, Creativity, and the Arts, 1, 80-90.

Külpe, O. (1897). Introduction to Philosophy. London: Swan Sonnenschein \& Co.

Külpe, O. (1907). Der gegenwärtige Stand der experimentellen Ästhetik. In F. Schumann (Ed.), Bericht über den II. Kongreß für experimentelle Psychologie in Würzburg vom 18. bis 21. April 1906 (pp. 1-57). Leipzig: Barth.

Külpe, O. (1921). Grundlagen der Ästhetik. Leipzig: S. Hirzel.

Leder, H., Belke, B., Oeberst, A., \& Augustin, D. (2004). A model of aesthetic appreciation and aesthetic judgments. British Journal of Psychology, 95, 489-508.

Leder, H., \& Nadal, M. (2014). Ten years of a model of aesthetic appreciation and aesthetic judgments: The aesthetic episode - Developments and challenges in empirical aesthetics. British Journal of Psychology, 105(4), 443-464. https://doi.org/10.1111/bjop.12084

Leder, H., Tinio, P. P. L., Brieber, D., Kröner, T., Jacobsen, T., \& Rosenberg, R. (2019). 
Symmetry is not a universal law of beauty. Empirical Studies of the Arts, 37, 104-114.

Levinson, J. (2003). Philosophical aesthetics: An overview. In J. Levinson (Ed.), The Oxford handbook of aesthetics (pp. 3-24). Oxford: Oxford University Press.

Locher, P. J., Smith, K. S., \& Smith, L. F. (2001). The influence of presentation format and viewer training in the visual arts on the perception of pictorial and aesthetic qualities of paintings. Perception, 30, 449-465.

Locher, P., Smith, L., \& Smith, J. (1999). Original paintings versus slide and computer reproductions: A comparison of viewer responses. Empirical Studies of the Arts, 17, $121-129$.

Logasa, H. A., \& Wright, M. M. (1930). Tests for the appreciation of literature. Bloomington, Ill.: Public School Publishing Co.

Lundholm, H. (1921). The affective tone of lines: Experimental researches. Psychological Review, 28, 43-60.

Machado, P., Romero, J., Cardoso, A., \& Santos, A. (2005). Partially interactive evolutionary artists. New Generation Computing, 23, 143-155.

Machado, P., Romero, J., \& Manaris, B. (2008). Experiments in Computational Aesthetics. An Iterative Approach to Stylistic Change in Evolutionary Art. In J. Romero \& P. Machado (Eds.), The Art of Artificial Evolution. Natural Computing Series (pp. 381415). Berlin: Springer.

Madison, T. H. (1942). Interval discrimination as a measure of musical aptitude. Archives of Psychology1, 268, 5-99.

Makin, A. D. J. (2017). The gap between aesthetic science and aesthetic experience. Journal of Consciousness Studies, 24, 184-213.

Marin, M. M., Lampatz, A., Wandl, M., \& H., L. (2016). Berlyne revisited: Evidence for the multifaceted nature of hedonic tone in the appreciation of paintings and music. Frontiers 
in Human Neuroscience, 10, 536. https://doi.org/10.3389/fnhum.2016.00536

Martin, L. J. (1906). An experimental study of Fechner's principles of aesthetics. Psychological Review, 142-219.

Martindale, C. (1984). The pleasures of thought: A theory of cognitive hedonics. The Journal of Mind and Behavior, 5, 49-80.

Martindale, C. (1988). Aesthetics, Psychobiology, and Cognition. In F. Farley \& R. Neperud (Eds.), The foundations of aesthetics, art, and art education (pp. 7-42). New York: Praeger.

Martindale, C. (1990). The clockwork muse: The predictability of artistic styles. New York, NY: Basic Books.

Martindale, C., \& Moore, K. (1988). Priming, prototypicality, and preference. Journal of Experimental Psychology: Human Perception and Performance, 14, 661-670.

Martindale, C., Moore, K., \& Borkum, J. (1990). Aesthetic preference: Anomalous findings for Berlyne's Psychobiological Theory. American Journal of Psychology, 103, 53-80.

Martindale, C., Moore, K., \& West, A. (1988). Relationship of preference judgments to typicality, novelty, and mere exposure. Empirical Studies of the Arts, 6, 79-96.

Mastandrea, S., Bartoli, G., \& Bove, G. (2009). Preferences for ancient and modern art museums: Visitor experiences and personality characteristics. Psychology of Aesthetics, Creativity, and the Arts, 3, 164-173.

McAdory, M. (1933). The construction and validation of an art test. New York, NY: Columbia University Press.

McCarthy, D. (1930). A study of the Seashore measures of musical talent. Journal of Applied Psychology, 437-455. https://doi.org/10.1037/h0073360

McManus, I. C., \& Wu, W. (2013). “The Square Is ... Bulky, Heavy, Contented, Plain, Good-Natured, Stupid ...": A Cross-Cultural Study of the Aesthetics and Meanings of 
Rectangles. Psychology of Aesthetics, Creativity, and the Arts, 7, 130-139.

https://doi.org/10.1037/a0030469

Meier, N. C. (1926). Aesthetic judgment as a measure of art talent. In University of Iowa Studies. Series on Aims and Progress of Research (Vol. 1). Iowa City: University of Iowa.

Meier, N. C. (1940). Meier art tests. I. Art judgment. Iowa City: State University of Iowa, Bureau of Educational Research and Service.

Meier, N. C. (1942). The Meier Art Judgment Test. Iowa City: Bureau of Educational Research and Service, University of Iowa.

Meier, N. C. (1963). Meier art tests. II. Aesthetic perception. Iowa City: Bureau of Educational Research and Service, University of Iowa.

Meier, N. C., \& Seashore, C. E. (1929). The Meier-Seashore Art Judgment Test. Iowa City: Bureau of Educational Research, University of Iowa,.

Menninghaus, W., Wagner, V., Wassiliwizky, E., Schindler, I., Hanich, J., Jacobsen, T., \& Koelsch, S. (2019). What are aesthetic emotions? . Psychological Review, 126, 171-195.

Mesquita, B., Barrett, L. F., \& Smith, E. R. (2010). The mind in context. New York: The Guilford Press.

Michaels, G. M. (1924). Color preferences according to age. The American Journal of Psychology, 35, 79-87.

Miller, C. A., \& Hübner, R. (2019). Two Routes to Aesthetic Preference, One Route to Aesthetic Inference. Psychology of Aesthetics, Creativity, and the Arts, advance on. https://doi.org/10.1037/aca0000241

Millis, K. (2001). Making meaning brings pleasure: The influene of titles on aesthetic experiences. Emotion, 1, 320-329.

Mitschke, V., Goller, J., \& Leder, H. (2017). Exploring everyday encounters with street art 
using a multimethod design. Psychology of Aesthetics, Creativity, and the Arts, 11, 276283.

Mühlenbeck, C. A., Liebal, K., Pritsch, C., \& Jacobsen, T. (2015). Gaze duration biases for colours in combination with dissonant and consonant sounds: a comparative eyetracking study with orangutans. Plos One, 10(10), e0139894.

Mühlenbeck, C., Jacobsen, T., Pritsch, C., \& Liebal, K. (2017). Cultural and Species Differences in Gazing Patterns for Marked and Decorated Objects: A Comparative EyeTracking Study. Frontiers in Psychology, Vol. 8, p. 6. Retrieved from https://www.frontiersin.org/article/10.3389/fpsyg.2017.00006

Mühlenbeck, C., Liebal, K., Pritsch, C., \& Jacobsen, T. (2016). Differences in the visual perception of symmetric patterns in orangutans (Pongo pygmaeus abelii) and two human cultural groups: a comparative eye-tracking study. Frontiers in Psychology, 7, 408. https://doi.org/10.3389/fpsyg.2016.00408

Munar, E., Gomez-Puerto, G., Call, J., \& Nadal, M. (2015). Common visual preference for curved contours in humans and great apes. PLoS ONE, 10(11). https://doi.org/10.1371/journal.pone.0141106

Myszkowski, N., Çelik, P., \& Storme, M. (2018). A meta-analysis of the relationship between intelligence and visual "Taste" measures. Psychology of Aesthetics, Creativity, and the Arts, 12, 24-33.

Myszkowski, N., \& Storme, M. (2017). Measuring "Good Taste" with the Visual Aesthetic Sensitivity Test-Revised (VAST-R). Personality and Individual Differences, 117, 91100.

Nadal, M. (2013). The experience of art. Insights from neuroimaging. Progress in Brain Research, 204, 135-158. https://doi.org/10.1016/B978-0-444-63287-6.00007-5

Nadal, M., Munar, E., Capó, M. À., Rosselló, J., \& Cela-Conde, C. J. (2008). Towards a 
framework for the study of the neural correlates of aesthetic preference. Spatial Vision, 21(3-5). https://doi.org/10.1163/156856808784532653

Nadal, M., \& Pearce, M. T. (2011). The Copenhagen Neuroaesthetics conference: Prospects and pitfalls for an emerging field. Brain and Cognition, 76(1), 172-183. https://doi.org/10.1016/j.bandc.2011.01.009

Nadal, M., \& Skov, M. (2018). The pleasure of art as a matter of fact. Proceedings of the Royal Society B: Biological Sciences, 285(1875). https://doi.org/10.1098/rspb.2017.2252

Neisser, U. (1967). Cognitive Psychology. Englewood Cliffs, NJ: Prentice Hall.

Omigie, D., Frieler, K., Bär, C., Muralikrishnan, R., Wald-Fuhrmann, M., \& Fischinger, T. (2019). Experiencing Musical Beauty: Emotional Subtypes and Their Physiological and Musico-Acoustic Correlates. Psychology of Aesthetics, Creativity, and the Arts, advance on. https://doi.org/10.1037/aca0000271

Ortmann, O. (1926). On the melodic relativity of tones. Psychological Monographs, 35, i-47. Ortmann, O. (1928). Tonal Intensity as an Aesthetic Determinant. The Musical Quarterly, 14, $178-191$.

Palumbo, L., \& Bertamini, M. (2016). The curvature effect: A comparison between preference tasks. Empirical Studies of the Arts, 34, 35-52.

Palumbo, L., Ruta, N., \& Bertamini, M. (2015). Comparing angular and curved shapes in terms of implicit associations and approach/avoidance responses. Plos One, 10, e0140043. https://doi.org/10.1371/journal.pone.0140043

Pelowski, M., Markey, P. S., Forster, M., Gerger, G., \& Leder, H. (2017). Move me, astonish me... delight my eyes and brain: The Vienna Integrated Model of top-down and bottomup processes in Art Perception (VIMAP) and corresponding affective, evaluative, and neurophysiological correlates. Physics of Life Reviews, 21, 80-125. 
Poffenberger, A. T., \& Barrows, B. E. (1924). The Feeling Value of Lines. Journal of Applied Psychology, 8, 187-205.

Prum, R. O. (2017). The Evolution of Beauty: How Darwin's Forgotten Theory of Mate Choice Shapes the Animal World—and Us. New York, NY: Doubleday.

Reber, R., Schwarz, N., \& Winkielman, P. (2004). Processing fluency and aesthetic pleasure: Is beauty in the perceiver's processing experience? Personality and Social Psychology Review, 8, 364-382.

Rosch, E., \& Mervis, C. B. (1975). Family resemblances: Studies in the internal structure of categories. Cognitive Psychology, 7, 573-605. https://doi.org/10.1016/00100285(75)90024-9

Rosch, E., Mervis, C. B., Gray, W. D., Johnson, D. M., \& Boyes-Braem, P. (1976). Basic objects in natural categories. Cognitive Psychology, 8, 382-439.

Ryan, M. J. (2018). A Taste for the Beautiful. The Evolution of Attraction. Princeton, NJ: Princeton University Press.

Santayana, G. (1904). What is Aesthetics? The Philosophical Review, 13, 320-327.

Schaefer, M., \& Rotte, M. (2007). Favorite brands as cultural objects modulate reward circuit. NeuroReport, 18, 141-145.

Schmidhuber, J. (2006). Developmental Robotics, Optimal Artificial Curiosity, Creativity, Music, and the Fine Arts. Connection Science, 18, 173-187.

Schwarz, K., Wieschollek, P., \& Lensch, H. P. A. (2018). Will People Like Your Image? Learning the Aesthetic Space. 2018 IEEE Winter Conference on Applications of Computer Vision (WACV), 2048-2057. https://doi.org/10.1109/WACV.2018.00226

Seeley, W. P. (2006). Naturalizing aesthetics: art and the cognitive neuroscience of vision. Journal of Visual Art Practice, 5, 195-213.

Seeley, W. P. (2011). What is the cognitive neuroscience of art ... and why should we care? 
American Society for Aesthetics Newsletter, 31, 1-4.

Seeley, W. P. (2014a). Empirical aesthetics. In M. Kelly (Ed.), Oxford Encyclopedia of Aesthetics (2nd ed.). New York, NY: Oxford University Press.

Seeley, W. P. (2014b). Philosophy of art and empirical aesthetics: resistance and rapprochement. In P. P. L. Tinio \& J. K. Smith (Eds.), The Cambridge handbook of the psychology of aesthetics and the arts (pp. 35-59). Cambridge: Cambridge University Press.

Segal, J. (1905). Die bewußte Selbsttäuschung als Kern des ästhetischen Genießen. Archiv Für Die Gesamte Psychologie, 6, 254-270.

Segal, J. (1906). Über die Wohlgefälligkeit einfacher räumlicher Formen: Eine psychologische-ästhetische Untersuchung. Archiv Für Die Gesamte Psychologie, 7, 55124.

Simonton, D. K. (1990). Psychology, science, and history: An introduction to historiometry. New Haven, CT: Yale University Press.

Simonton, D. K. (2018). Intellectual genius in the Islamic Golden Age: Cross-civilization replications, extensions, and modifications. Psychology of Aesthetics, Creativity, and the Arts, 12, 125-135.

Skamel, U. (2003). Beauty and sex appeal: Sexual selection of aesthetic preferences. In E. Voland \& K. Grammer (Eds.), Evolutionary Aesthetics (pp. 173-200). Berlin: SpringerVerlag.

Skov, M. (2019). Aesthetic appreciation: The view from neuroimaging. Empirical Studies of the Arts, 37, 220-248. https://doi.org/https://doi.org/10.1177/0276237419839257

Skov, M. (2020). Animal Preferences: Implications of Sexual Selection Research for Empirical Aesthetics. Psychology of Aesthetics, Creativity, and the Arts, in press. https://doi.org/10.13140/RG.2.2.21110.75847 
Skov, M., \& Nadal, M. (2018). Art is not special: An assault on the last lines of defense against the naturalization of the human mind. Reviews in the Neurosciences, 29(6). https://doi.org/10.1515/revneuro-2017-0085

Skov, M., \& Nadal, M. (2019). The Nature of Perception and Emotion in Aesthetic Appreciation: A Response to Makin's Challenge to Empirical Aesthetics. Psychology of Aesthetics, Creativity, and the Arts. https://doi.org/10.1037/aca0000278

Skov, M., \& Nadal, M. (2020). There are no aesthetic emotions: Comment on Menninghaus et al. (2019). Psychological Review, 127, 640-649.

Smith, S. M., \& Vela, E. (2001). Environmental context-dependent memory: A review and meta-analysis. Psychonomic Bulletin \& Review, 8, 203-220.

Sparshott, F. E. (1963). The structure of aesthetics. Toronto: Toronto University Press.

Stanton, H. M. (1928). Seashore measures of musical talent. Psychological Monographs, 2 , 135-144. https://doi.org/10.1037/h0093342

Staples, R. (1931). Color vision and color preference in infancy and childhood. Psychological Bulletin, 28, 297-308.

Sternberg, E. M., \& Wilson, M. A. (2006). Neuroscience and architecture: seeking common ground. Cell, 127, 239-242.

Stratton, G. M. (1923). The Color Red, and the Anger of Cattle. Psychological Review, (30), $321-325$.

Talebi, H., \& Milanfar, P. (2018). NIMA: Neural Image Assessment. IEEE Transactions on Image Processing, 27(8), 3998-4011. https://doi.org/10.1109/TIP.2018.2831899

Temme, J. E. V. (1992). Amount and kind of information in museums: its effects on visitors satisfaction and appreciation of art. Visual Arts Research, 2, 28-36.

Thorndike, E. L. (1916). Tests of esthetic appreciation. The Journal of Educational Psyhology, 7, 509-522. 
Thorndike, E. L. (1917). Individual differences in judgments of the beauty of simple forms. Psychological Review, 24, 147-153.

Tschacher, W., Greenwood, S., Kirchberg, V., Wintzerith, S., van den Berg, K., \& Tröndle, M. (2012). Physiological correlates of aesthetic perception of artworks in a museum. Psychology of Aesthetics, Creativity, and the Arts, 6, 96-103.

Ulrich, R. S. (1977). Visual landscape preference: a model and applications. ManEnvioronment Systems, 7, 279-293.

Ulrich, R. S. (1991). Effects of interior design on wellness: theory and recent scientific research. Journal of Health Care Interior Design, 3, 97-109.

Ulrich, R. S., Simons, R. F., Losito, B. D., Fiorito, E., Miles, M. A., \& Zelson, M. (1991). Stress recovery during exposure to natural and urban environments. Journal of Environmental Psychology, 11, 201-230.

Urgesi, C., Calvo-Merino, B., Haggard, P., \& Aglioti, S. M. (2007). Transcranial magnetic stimulation reveals two cortical pathways for visual body processing. The Journal of Neuroscience, 27, 8023-8030.

Van Geert, E., \& Wagemans, J. (2019). Order, Complexity, and Aesthetic Preferences for Neatly Organized Compositions. Psychology of Aesthetics, Creativity, and the Arts, advance on. https://doi.org/10.1037/aca0000276

Vartanian, O., \& Goel, V. (2004). Neuroanatomical correlates of aesthetic preference for paintings. NeuroReport, 15, 893-897.

Vartanian, O., \& Skov, M. (2014). Neural correlates of viewing paintings: Evidence from a quantitative meta-analysis of functional magnetic resonance imaging data. Brain and Cognition, 87, 52-56.

Vessel, E A, Starr, G. G., \& Rubin, N. (2012). The brain on art: intense aesthetic experience activates the default mode network. Frontiers in Human Neuroscience, 6, 66. doi: 
10.3389/fnhum.2012.00066.

Vessel, Edward A., Maurer, N., Denker, A. H., \& Starr, G. G. (2018). Stronger shared taste for natural aesthetic domains than for artifacts of human culture. Cognition, 179, 121131. https://doi.org/10.1016/j.cognition.2018.06.009

Voland, E., \& Grammer, K. (2003). Evolutionary Aesthetics. Berlin: Springer.

von Soest, T., Kvalem, I. L., Roald, H. E., \& Skolleborg, K. C. (2009). The effects of cosmetic surgery on body image, self-esteem, and psychological problems. Journal of Plastic, Reconstructive \& Aesthetic Surgery, 62(10), 1238-1244.

https://doi.org/https://doi.org/10.1016/j.bjps.2007.12.093

Voss, M. D. (1939). A study of conditions affecting the functioning of the art appreciation process at the child-level. Psychological Monographs, 48, 1-39.

Washburn, M. F., Haight, D., \& Regensburg, J. (1921). The Relation of the Pleasantness of Color Combinations to That of the Colors Seen Singly. The American Journal of Psychology, 32, 145-146.

Weber, C. O. (1931). The aesthetics of rectangles and theories of affection. Journal of Applied Psychology, 31, 310-318.

Welsh, G. S., \& Barron, F. (1949). Barron-Welsh Art Scale. Palo Alto: Consulting Psychology Press.

Westphal-Fitch, G., \& Fitch, W. T. (2015). Towards a comparative approach to empirical aesthetics. In J. P. Huston, M. Nadal, F. Mora, A. Agnati, \& C. J. Cela-Conde (Eds.), Art, aesthetics and the brain (pp. 386-407). Oxford: Oxford University Press.

Williams, E. D., Winter, L., \& Woods, J. M. (1938). Tests of literary appreciation. British Journal of Educational Psychology, 8, 265-284.

Wing, H. D. (1941). A factorial study of musical tests. British Journal of Psychology, 31, $341-355$. 
Witmer, L. (1894). Zur experimentellen Aesthetik einfacher räumlicher Formverhältnisse. Philosophische Studien, 9, 96-144.

Yokoyama, M. (1921). Affective Tendency as Conditioned by Color and Form. The American Journal of Psychology, 32, 81-107.

Zaidel, D. W. (2005). Neuropsychology of Art: Neurological, Cognitive, and Evolutionary Perspectives. Hove, England: Psychology Press.

Zaidel, D. W., Nadal, M., Flexas, A., \& Enric, M. (2013). An evolutionary approach to art and aesthetic experience. Psychology of Aesthetics, Creativity, and the Arts, 7(1). https://doi.org/10.1037/a0028797

Zeki, S. (1999). Inner Vision. An Exploration of Art and the Brain. Oxford: Oxford University Press. 